\title{
Characterizing low affinity epibatidine binding to $\alpha 4 \beta 2$ nicotinic acetylcholine receptors with ligand depletion and nonspecific binding
}

\author{
Alexandra M Person ${ }^{1}$ and Gregg B Wells ${ }^{1,2,3^{*}}$
}

\begin{abstract}
Background: Along with high affinity binding of epibatidine $\left(K_{\mathrm{d} 1} \approx 10 \mathrm{pM}\right)$ to $\alpha 4 \beta 2$ nicotinic acetylcholine receptor (nAChR), low affinity binding of epibatidine $\left(K_{\mathrm{d} 2} \approx 1-10 \mathrm{nM}\right)$ to an independent binding site has been reported. Studying this low affinity binding is important because it might contribute understanding about the structure and synthesis of $\alpha 4 \beta 2 \mathrm{nAChR}$. The binding behavior of epibatidine and $\alpha 4 \beta 2 \mathrm{AChR}$ raises a question about interpreting binding data from two independent sites with ligand depletion and nonspecific binding, both of which can affect equilibrium binding of $\left.{ }^{3} \mathrm{H}\right]$ epibatidine and $\alpha 4 \beta 2 \mathrm{nAChR}$. If modeled incorrectly, ligand depletion and nonspecific binding lead to inaccurate estimates of binding constants. Fitting total equilibrium binding as a function of total ligand accurately characterizes a single site with ligand depletion and nonspecific binding. The goal of this study was to determine whether this approach is sufficient with two independent high and low affinity sites.
\end{abstract}

Results: Computer simulations of binding revealed complexities beyond fitting total binding for characterizing the second, low affinity site of $\alpha 4 \beta 2 \mathrm{nAChR}$. First, distinguishing low-affinity specific binding from nonspecific binding was a potential problem with saturation data. Varying the maximum concentration of $\left[{ }^{3} \mathrm{H}\right]$ epibatidine,

simultaneously fitting independently measured nonspecific binding, and varying $\alpha 4 \beta 2 \mathrm{nAChR}$ concentration were effective remedies. Second, ligand depletion helped identify the low affinity site when nonspecific binding was significant in saturation or competition data, contrary to a common belief that ligand depletion always is detrimental. Third, measuring nonspecific binding without $\alpha 4 \beta 2 \mathrm{nAChR}$ distinguished better between nonspecific binding and low-affinity specific binding under some circumstances of competitive binding than did presuming nonspecific binding to be residual $\left.{ }^{3} \mathrm{H}\right]$ epibatidine binding after adding a large concentration of cold competitor. Fourth, nonspecific binding of a heterologous competitor changed estimates of high and low inhibition constants but did not change the ratio of those estimates.

Conclusions: Investigating the low affinity site of $\alpha 4 \beta 2 \mathrm{nAChR}$ with equilibrium binding when ligand depletion and nonspecific binding are present likely needs special attention to experimental design and data interpretation beyond fitting total binding data. Manipulation of maximum ligand and receptor concentrations and intentionally increasing ligand depletion are potentially helpful approaches.

\section{Background}

Ligand depletion can significantly affect estimates for dissociation $\left(K_{\mathrm{d}}\right)$ or inhibition $\left(K_{\mathrm{i}}\right)$ constants from equilibrium binding data of epibatidine (EB) and $\alpha 4 \beta 2$ nicotinic acetylcholine receptor (nAChR) because of the high affinity of $\mathrm{EB}\left(K_{\mathrm{d} 1} \approx 10 \mathrm{pM}\right)$. Errors from ligand depletion arise

\footnotetext{
* Correspondence: gbwells@tamu.edu

'Department of Molecular and Cellular Medicine, Texas A\&M University

System Health Science Center, College Station, TX 77843-1114, USA

Full list of author information is available at the end of the article
}

from inappropriately assuming that free ligand concentration equals total ligand concentration while using total ligand concentration as the independent variable for modeling the binding data. The assumption is attractive because total ligand concentration as the independent variable is suitable for least squares fitting of binding data $[1,2]$. Ligand depletion can be minimized when designing binding experiments with EB and $\alpha 4 \beta 2$ nAChR. Radiolabeled EB with higher specific activity (for example, ${ }^{125} \mathrm{I}$ instead of ${ }^{3} \mathrm{H}$ ) can lead to less ligand depletion by allowing
Ciomed Central

(c) 2011 Person and Wells; licensee BioMed Central Ltd. This is an Open Access article distributed under the terms of the Creative Commons Attribution License (http://creativecommons.org/licenses/by/2.0), which permits unrestricted use, distribution, and reproduction in any medium, provided the original work is properly cited. 
a smaller concentration of $\alpha 4 \beta 2 \mathrm{nAChR}$ to produce useful data. A larger reaction volume at a fixed mole quantity of $\alpha 4 \beta 2 \mathrm{nAChR}$ reduces ligand depletion by reducing the difference between free and total concentration of radiolabeled EB. These avoidance strategies based on design of experiments, however, might be difficult to use in some situations. For example, a newly developed and ${ }^{3} \mathrm{H}$-labeled EB derivative might be available only with low specific activity. Large reaction volumes might be impractical for numerous samples associated with high throughput screening [3]. When ligand depletion cannot easily be avoided, how can data with both ligand depletion and nonspecific binding (NSB) be correctly interpreted from $\mathrm{EB}$ and $\alpha 4 \beta 2 \mathrm{nAChR}$ ?

Effects of ligand depletion on binding data have long been recognized, leading to models that correctly include ligand depletion with single and multiple specific binding sites [3-9]. For [ $\left.{ }^{3} \mathrm{H}\right] \mathrm{EB}$, a ligand with relatively low specific activity, and $\alpha 4 \beta 2 \mathrm{nAChR}$, ligand depletion has been recognized and avoided as a potentially confounding factor for interpreting binding data [10-17]. Alternatively, one site and two sites models for estimating binding constants have included ligand depletion with negligible NSB [18]. Combining ligand depletion and NSB, however, imposes additional demands on binding models. For example, specific binding cannot be calculated simply by subtracting NSB from total binding. Instead, a binding model including both ligand depletion and NSB must fit total binding [6] as has been shown with one specific binding site [19]. In addition to the high potency or high affinity site, functional data from electrophysiology and ${ }^{86} \mathrm{Rb}^{+}$flux [20-41] and binding data $[12,18,20,42,43]$ for $\alpha 4 \beta 2$ or $\alpha 4 \beta 2$-containing $\mathrm{nAChR}$ suggest a second, low potency or low affinity specific binding site. The difference in agonist potency at the two sites in functional assays has been attributed to $\alpha 4 \beta 2 \mathrm{nAChR}$ with different $\alpha: \beta$ stoichiometries $[21,25,28,30,33] .(\alpha 4)_{2}(\beta 2)_{3}$ contributes high potency and $(\alpha 4)_{3}(\beta 2)_{2}$ contributes low potency. Binding data from our laboratory suggest two independent sites and not two cooperative sites [18]. The physical basis of low affinity equilibrium binding of $\left[{ }^{3} \mathrm{H}\right]$ EB detected under some conditions and the relationship between the low affinity site observed by equilibrium binding and the low potency site observed by functional methods are not known. On the other hand, a single binding site has been suggested for $\alpha 4 \beta 2 \mathrm{nAChR}[12,14]$ and for extracellular domain $\alpha 4 \beta 2 \mathrm{nAChR}$ [18] from binding data. Photolabeling of $\alpha 4 \beta 2$ with $\left[{ }^{3} \mathrm{H}\right] \mathrm{EB}$ also identified a single binding site [44]. Models of $\alpha 4 \beta 2$ nAChR binding data, therefore, should not assume the presence of high and low affinity sites. Instead, an interpretation of binding data needs to test the hypothesis of one binding site versus more than one binding site.
How does interpreting binding data with ligand depletion with NSB and a single binding site $[19,45]$ need to be modified when a second, low-affinity specific binding site might be present from $\alpha 4 \beta 2$ nAChR? Detecting and accurately interpreting properties of the low affinity site is important because of the potential biological relevance of the low-affinity specific site. The low affinity binding site might reflect biologically important roles for $\alpha 4 \beta 2$ $\mathrm{nAChR}$, reflect a variant structure of the agonist binding site, or give insight into the assembly of $\alpha 4 \beta 2 \mathrm{nAChR}$. The goal of this study was to determine, using computational modeling, whether fitting total binding is sufficient for characterizing the low affinity binding site from $\alpha 4 \beta 2$ $\mathrm{nAChR}$ in the context of ligand depletion and NSB. The modeling simulated saturation binding, homologous competition, and heterologous competition. The experimental foundation for the modeling was reported previously with $K_{\mathrm{d} 1}=13 \mathrm{pM}$ for the high affinity site and $K_{\mathrm{d} 2}=12 \mathrm{nM}$ for the low affinity site [18]. The findings are potentially relevant to other ligands and receptors when two or more specific binding sites are possible and when ligand depletion and NSB affect binding data.

\section{Methods}

\section{Equations of the models}

For an introduction to interpreting equilibrium binding with ligand depletion and NSB, see Swillens [19] and Motulsky and Christopoulos [7]. The models of saturation binding and homologous and heterologous competition were based on mass action equations and conservation of mass (Figure 1). Figure 1 shows the notations for the states and equations for the equilibrium dissociation and inhibition constants of the models. Equations for a model were solved numerically within a Microsoft Excel environment using the Maple version 13 or 14 (Maplesoft) add-in. Parameters of a model were optimized to simulated data with the method of least squares using Excel and the Premium Solver Platform (Frontline Systems). Values of parameters were constrained to physically valid values.

Analytical solutions of cubic equations are available that describe ligand depletion (with and without NSB) of two binding sites and one ligand or of two sites with homologous competition $[3,9,18,46,47]$. Analytical solutions of a quartic polynomial describing ligand depletion and NSB of three binding sites and one ligand or of two binding sites with homologous competition can be derived from the general solution of a quartic polynomial [48]. Numerical solutions were used in this investigation because of the relative ease of implementation and the usefulness of numerical solutions when roots of quintic and higher order polynomials are needed to describe ligand depletion but for which analytical solutions are not available. For example, roots of a sixth order polynomial are needed to 


\section{Saturation binding for 2 sites}

$$
\begin{aligned}
& \mathrm{R} 1+\mathrm{L} \underset{K_{\mathrm{dl}}}{\rightleftharpoons} \mathrm{R} 1 \mathrm{~L} \\
& \mathrm{R} 2+\mathrm{L} \stackrel{K_{\mathrm{d} 2}}{\rightleftharpoons} \mathrm{R} 2 \mathrm{~L} \\
& K_{\mathrm{d} 1}=\frac{\mathrm{R} 1 * \mathrm{~L}}{\mathrm{R} 1 \mathrm{~L}} \\
& K_{\mathrm{d} 2}=\frac{\mathrm{R} 2 * \mathrm{~L}}{\mathrm{R} 2 \mathrm{~L}} \\
& \mathrm{R} 1 \mathrm{~T}=\mathrm{R} 1+\mathrm{R} 1 \mathrm{~L} \\
& \mathrm{R} 2 \mathrm{~T}=\mathrm{R} 2+\mathrm{R} 2 \mathrm{~L} \\
& \mathrm{LT}=\mathrm{R} 1 \mathrm{~L}+\mathrm{R} 2 \mathrm{~L}+\mathrm{L}+\alpha_{\mathrm{L}} * \mathrm{~L} \\
& \mathrm{NSB}_{\mathrm{L}}=\alpha_{\mathrm{L}} * \mathrm{~L} \\
& \text { unknowns: R1, R2, L, R1L, R2L } \\
& \text { parameters: } K_{\mathrm{d} 1}, K_{\mathrm{d} 2}, \mathrm{R} 1 \mathrm{~T}, \mathrm{R} 2 \mathrm{~T}, \alpha_{\mathrm{L}} \\
& \mathrm{R} 1+\mathrm{L} \stackrel{K_{\mathrm{dl}}}{\rightleftharpoons} \mathrm{R} 1 \mathrm{~L}
\end{aligned}
$$

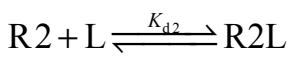

$$
\begin{aligned}
& \mathrm{R} 1+\mathrm{B} \stackrel{K_{\mathrm{i}}}{\rightleftharpoons} \mathrm{R} 1 \mathrm{~B} \\
& \mathrm{R} 2+\mathrm{B} \stackrel{K_{\mathrm{i} 2}}{\rightleftharpoons} \mathrm{R} 2 \mathrm{~B} \\
& \mathrm{R} 1 \mathrm{~T}=\mathrm{R} 1+\mathrm{R} 1 \mathrm{~L}+\mathrm{R} 1 \mathrm{~B} \\
& \mathrm{R} 2 \mathrm{~T}=\mathrm{R} 2+\mathrm{R} 2 \mathrm{~L}+\mathrm{R} 2 \mathrm{~B} \\
& \mathrm{LT}=\mathrm{R} 1 \mathrm{~L}+\mathrm{R} 2 \mathrm{~L}+\mathrm{L}+\alpha_{\mathrm{L}} * \mathrm{~L} \\
& \mathrm{BT}=\mathrm{R} 1 \mathrm{~B}+\mathrm{R} 2 \mathrm{~B}+\mathrm{B}+\alpha_{\mathrm{B}} * \mathrm{~B} \\
& \mathrm{NSB}_{\mathrm{L}}=\alpha_{\mathrm{L}} * \mathrm{~L} \\
& \mathrm{NSB}_{\mathrm{B}}=\alpha_{\mathrm{B}} * \mathrm{~B}
\end{aligned}
$$

Figure 1 Equations for the binding models are based on the law of mass action and conservation of mass. Two mass action equations (c)-(d) for dissociation constants derived from (a)-(b) and three conservation of mass equations (e)-(g) formed the five equations solved simultaneously for the two sites model $\left.\right|_{\text {total }}$ for saturation binding. Four mass action equations for dissociation constants derived from (i)-(I) and four conservation of mass equations $(m)-(p)$ formed the eight equations solved simultaneously for the two sites model total $_{\text {for homologous or heterologous }}$ competition. $L$ was the independent variable for two sites model free for saturation binding, which did not include Eq. (g). B was the independent variable of two sites modelfree for competition, which did not include Eq. (p). One site model $\left.\right|_{\text {total }}$ excluded terms referring to the second site. The two sites model for saturation binding that ignored ligand depletion was based on Eqs. (c)-(f) and assumed LT $=\mathrm{L}$. Notation: $\alpha_{\mathrm{L}}=$ constant describing NSB of radioligand; $K_{\mathrm{d} 1}=$ dissociation constant of high affinity binding site; $L=$ free radioligand; $\mathrm{LT}=$ total radioligand; $\mathrm{NSB}_{\mathrm{L}}=$ nonspecific binding of radioligand; $\mathrm{R} 1=$ unbound first binding site; $\mathrm{R} 1 \mathrm{~L}=$ radioligand bound to first site; R1T = total high affinity binding site; $B=$ free competitor (blocker). With analogous notations, the index " 2 " in these equations refers to the low affinity binding site. describe heterologous competition with two sites and ligand depletion and NSB, which precludes an analytical solution.

\section{Data generation and model fitting}

True binding behaviors (i.e., noiseless data) were defined as the output from two-sites models using defined values of parameters and free ligand concentration as the independent variable (two sites model $\mathrm{f}_{\text {free}}$ ). Noise was superimposed by adding, to each noise-free data point, a random number selected from a standard normal distribution with a constant standard deviation (SD) determined by context. The SD value was constant along the $x$-axis. In some cases, noise was described by the maximum signal to noise ratio $(\mathrm{S} / \mathrm{N})$. The $\mathrm{SD}$ for noise was the maximum signal in the noiseless data divided by the maximum signal to noise ratio (i.e., $\mathrm{SD}=$ (maximum signal)/(stated maximum $\mathrm{S} / \mathrm{N})$ ). Multiple data sets with different SD values for noise were fitted simultaneously by weighting, by the inverse of the variance of the noise, the contribution of a data set to the sum of squares. Total concentration of added ligand was the independent variable for the one site model $_{\text {total }}$ and two sites model $_{\text {total }}$ when fitting noiseless and noisy data that included NSB. All results are displayed using total concentration on the $x$-axis. All ligand concentrations appearing in the text refer to total concentration unless otherwise noted. The two sites model for saturation binding that ignored ligand depletion assumed that LT $=\mathrm{L}$. The two sites model of apparent specific saturation binding was based on equations (c)-(g) and assumed $\alpha$ $=0$ in equation (g) (Figure 1). Apparent specific binding was the difference between total binding and apparent NSB. Apparent NSB was defined as NSB measured independently without $\alpha 4 \beta 2 \mathrm{nAChR}$ and equaled $\alpha /(1+\alpha)^{*}$ (total $\left[{ }^{3} \mathrm{H}\right] \mathrm{EB}$ ). The Hill equation (Eq. (1)) for characterizing binding data by fitting with SigmaPlot 11 was:

$$
y=A_{0} /\left(1+\left(K_{0.5} / x\right)^{n}\right)
$$

Data were generated with the following parameter values published by our laboratory [18] unless otherwise stated: $K_{\mathrm{d} 1}=0.013 \mathrm{nM}$ and $K_{\mathrm{d} 2}=12 \mathrm{nM}$ for $\left[{ }^{3} \mathrm{H}\right]$ EB; $K_{\mathrm{i} 1}=0.84$ and $K_{\mathrm{i} 2}=775 \mathrm{nM}$ for nicotine; fraction of $\mathrm{R} 1 \mathrm{~T}=0.84$; fraction of $\mathrm{R} 2 \mathrm{~T}=0.16$ (see Figure 1 for notation). When a R1T concentration is stated, the corresponding $\mathrm{R} 2 \mathrm{~T}$ concentration is implied.

\section{Statistics}

The one site models for saturation binding and competition data were simpler cases of the two sites models, making these two types of models nested [7]. Qualities of fit of the two types of models, therefore, were compared with the F-test [49]. The level of significance for 
hypothesis testing was 0.05 . The confidence level for a confidence interval (CI) was $95 \%$. CIs for dissociation constants and average $p$ values were based on logarithmic values.

\section{Results}

Effects of ligand depletion and NSB on saturation binding to two specific sites

The two sites model free $_{\text {generated errorless binding data }}$ using free $\left[{ }^{3} \mathrm{H}\right] \mathrm{EB}$ as the independent variable to investigate how ligand depletion without NSB affected saturation binding behavior. Increasing the concentration of binding sites increased ligand depletion, shifted the total binding curve to the right, increased the steepness of the curve, and obscured the distinctive contour of the low affinity binding site (Figure 2A). The binding contour of the high affinity site began shifting noticeably to the right and showed an increasingly sharp bend at $\left[{ }^{3} \mathrm{H}\right]$ $\mathrm{EB}=\mathrm{R} 1 \mathrm{~T}$ as R1T increased beyond $K_{\mathrm{d} 1}(0.013 \mathrm{nM})$ (Figure $2 \mathrm{~B})$. The binding contour of the low affinity site started shifting rightward as R1T approached $K_{\mathrm{d} 2}(12 \mathrm{nM})$. The rightward shift in the binding curves with ligand depletion means that relying on $\mathrm{K}_{0.5}$ as an estimate of $K_{\mathrm{d}}$ overestimates dissociation constants. Eq. (2)

$$
K_{\mathrm{d} 1}=\mathrm{K}_{0.5, \mathrm{high}}-(\mathrm{R} 1 \mathrm{~T} / 2)
$$

correctly estimated $K_{\mathrm{d} 1}$ from the half-maximum for

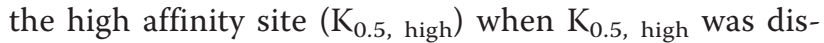
tinct $[5,50]$. Eq. (2), however, became increasingly difficult to use as rightward shift of the binding curve from the high affinity site led to overlap with the binding curve from the low affinity site.

The two sites model free $_{\text {generated errorless binding data }}$ with both ligand depletion and NSB to investigate how combining NSB with ligand depletion affected binding behavior. The effect of NSB depended on the extent of ligand depletion. With negligible ligand depletion at R1T $=0.0001 \mathrm{nM}$ (Figure 3A), NSB with $\alpha=10^{-6}$ started obscuring the binding contour from the low affinity site. NSB with $\alpha=10^{-3}$ obscured binding to the high affinity site. With significant ligand depletion at $\mathrm{R} 1 \mathrm{~T}=0.3 \mathrm{nM}$ (Figure 3B), NSB with $\alpha=10^{-4}$ obscured the binding contour from the low affinity site. With extreme ligand depletion at $\mathrm{R} 1 \mathrm{~T}=300 \mathrm{nM}$ (Figure $3 \mathrm{C}$ ), the contributions to total binding from the high affinity site and the low affinity site were not distinct even without NSB. NSB with $\alpha=1$ obscured specific binding to the high affinity site. Increasing ligand depletion also affected how NSB depended on total $\left[{ }^{3} \mathrm{H}\right] \mathrm{EB}$ concentration. The leftward shift in NSB with each $\log$ unit increase in $\alpha$ was relatively uniform when ligand depletion was negligible at $\mathrm{R} 1 \mathrm{~T}=10^{-4} \mathrm{nM}$ (Figure 3D). The leftward shift in NSB with each log unit increase in $\alpha$, however, became nonuniform when ligand depletion

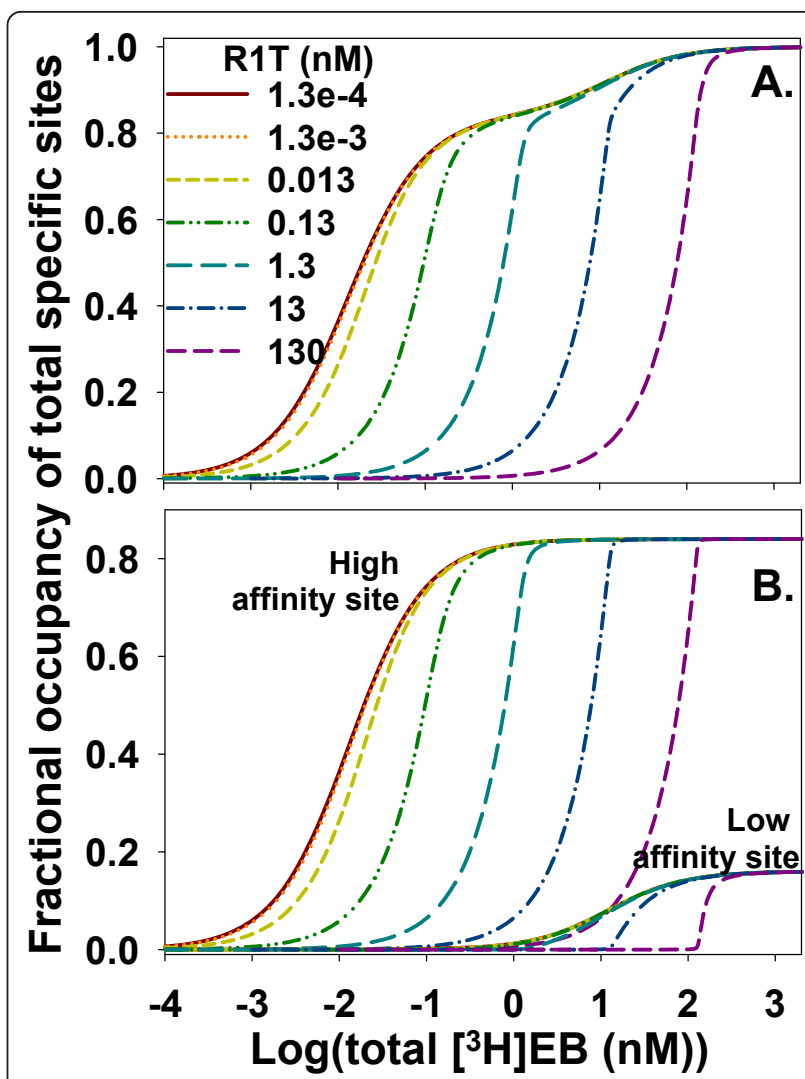

Figure 2 Ligand depletion shifts the binding curve rightward and obscures distinct features of the two binding sites. A. Fractional occupancy of total specific binding sites is shown at various concentrations of R1T. Increasing total binding sites increases ligand depletion, which shifts the total binding curve rightward. Ligand depletion also distorts the two sigmoidal features arising from binding to the high and low affinity sites. B. The fractional occupancies of high and low affinity sites are shown separately. The legend in A applies to B. Fractional occupancies of the low affinity site are clustered in the lower right corner of the plot. Only lines from R1T values of 13 and $130 \mathrm{nM}$ are distinct for the low affinity site. The leftmost line from the low affinity site arises from overlap of the lines from the first five concentrations of binding sites. Binding was calculated with two sites model $\left.\right|_{\text {reee. }}$.

became large (Figure 3E; R1T $=0.3 \mathrm{nM}$ ) or extreme (Figure 3F; R1T = $300 \mathrm{nM}$ ).

\section{Modeling specific binding and NSB as total binding}

How can dissociation constants be estimated when both ligand depletion and NSB contribute significantly to $\left[{ }^{3} \mathrm{H}\right]$ EB binding? An effective approach when ligand depletion is negligible is to calculate specific binding as the difference between total binding and NSB measured without $\alpha 4 \beta 2$ nAChR (apparent NSB). In accord with a one binding site model including ligand depletion and NSB [19], this approach was incorrect when ligand depletion was significant (Figure 3G and 3H). NSB shifted rightward from the apparent NSB as R1T increased because 


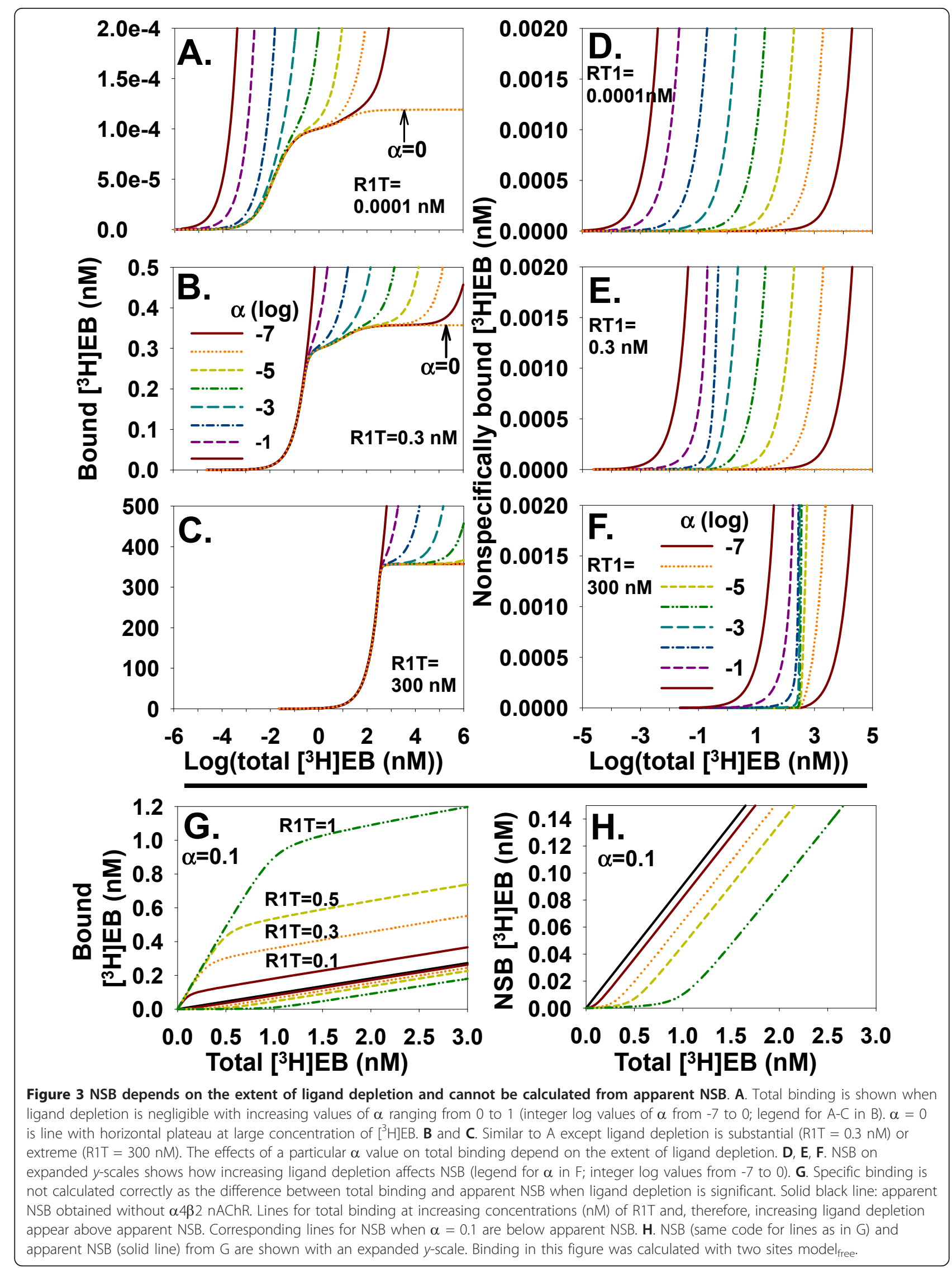


increasing R1T decreased the free $\left[{ }^{3} \mathrm{H}\right] \mathrm{EB}$ concentration for a given total concentration of $\left[{ }^{3} \mathrm{H}\right] \mathrm{EB}$. Subtracting apparent NSB from total binding led to calculated specific binding that was shifted rightward and downward compared to true specific binding (Figure 4A). This effect led to overestimating the values of $K_{\mathrm{d} 1}$ and $K_{\mathrm{d} 2}$ (Figure $4 \mathrm{~B}$ and $4 \mathrm{C}$ ), overestimating R1T (Figure $4 \mathrm{D}$ and $4 \mathrm{E}$ ), and underestimating R2T (Figure 4D and 4E) as ligand depletion increased. The difference between total binding and NSB equals specific binding by definition. These results, however, showed NSB when $\alpha 4 \beta 2 \mathrm{nAChR}$ was present was not equal to NSB when $\alpha 4 \beta 2 \mathrm{nAChR}$ was absent (apparent NSB). Specific binding, therefore, did not equal the result of subtracting apparent NSB from total binding. This inequality arose because NSB with $\alpha 4 \beta 2$ nAChR present did not equal apparent NSB when ligand depletion was significant. This observation has been made previously for a one site model [19].

Specific binding and NSB of $\left[{ }^{3} \mathrm{H}\right] \mathrm{EB}$ and $\alpha 4 \beta 2 \mathrm{nAChR}$ needed to be modeled together as total binding using the two sites model $_{\text {total }}$. This conclusion was consistent with the findings from a general one site model [19]. Accuracy of the two sites model total $_{\text {for calculating }}$ saturation binding data was tested by comparing predicted $\left[{ }^{3} \mathrm{H}\right] \mathrm{EB}$ binding to $\left[{ }^{3} \mathrm{H}\right] \mathrm{EB}$ binding calculated with two sites model $\left.\right|_{\text {free }}$. The concentration of bound $\left[{ }^{3} \mathrm{H}\right] \mathrm{EB}$ calculated by the two methods agreed to at least fourteen significant digits across this range of parameters: $10^{-6} \mathrm{nM} \leq \mathrm{R} 1 \mathrm{~T} \leq 10^{4} \mathrm{nM}$ and $0 \leq \alpha \leq 10^{2}$ with $10^{-6}$ $\mathrm{nM} \leq\left[{ }^{3} \mathrm{H}\right] \mathrm{EB}_{\text {free }} \leq 10^{6} \mathrm{nM}$. These results confirmed the accuracy of the binding calculations using the two sites model $_{\text {total }}$.

\section{Potential for failing to identify low-affinity specific binding when modeling only total saturation binding}

An important role for the two sites model $_{\text {total }}$ is to estimate dissociation constants and binding site concentrations from noisy binding data. These estimates, however, are valid only when the two sites model $\mathrm{t}_{\text {total }}$ fits data better than does the one site model $_{\text {total }}$ according to statistical testing. Under what circumstances are binding data from the two sites of $\alpha 4 \beta 2$ $n A C h R$ adequately explained by the one site model $\mathrm{total}_{\text {? }}$ ? In these situations, specific binding to the low affinity site is indistinguishable from high-affinity specific binding, NSB, or noise. On the other hand, what circumstances favor identifying the low-affinity specific binding site?

Deriving a computational expression for NSB from the general expression for binding to a single site suggested potential confusion between low-affinity specific binding and NSB as defined in Figure 1 (symbols similar to Figure 1):

$$
\begin{aligned}
& K_{\mathrm{d}}=\left(\frac{\mathrm{R}}{\mathrm{RL}}\right) * \mathrm{~L}_{\mathrm{f}} \\
& \mathrm{RL}_{\mathrm{NSB}}=\left(\frac{\mathrm{R}_{\mathrm{NSB}}}{K_{\mathrm{d}, \mathrm{NSB}}}\right) * \mathrm{~L}_{\mathrm{f}}=\left(\frac{\mathrm{RT}_{\mathrm{NSB}}}{K_{\mathrm{d}, \mathrm{NSB}}}\right) * \mathrm{~L}_{\mathrm{f}} \\
& \mathrm{RL}_{\mathrm{NSB}}=\mathrm{NSB}=\alpha^{*} \mathrm{~L}_{\mathrm{f}}
\end{aligned}
$$

where $\alpha=\left(\mathrm{RT}_{\mathrm{NSB}} / K_{\mathrm{d}, \mathrm{NSB}}\right)$ and $\mathrm{R}_{\mathrm{NSB}}=\mathrm{RT}_{\mathrm{NSB}}$ by the definition of homogeneous NSB. If NSB arises from a collection of heterogeneous sites, then

$$
\begin{aligned}
& \mathrm{RL}_{\mathrm{NSB}, \text { total }}=\left(\frac{\mathrm{R}_{\mathrm{NSB}, 1}}{K_{\mathrm{d}, \mathrm{NSB}, 1}}+\frac{\mathrm{R}_{\mathrm{NSB}, 2}}{K_{\mathrm{d}, \mathrm{NSB}, 2}}+\cdots\right) * \mathrm{~L}_{\mathrm{f}} \\
& \mathrm{RL}_{\mathrm{NSB}, \text { total }}=\left(\frac{\mathrm{RT}_{\mathrm{NSB}, 1}}{K_{\mathrm{d}, \mathrm{NSB}, 1}}+\frac{\mathrm{RT}_{\mathrm{NSB}, 2}}{K_{\mathrm{d}, \mathrm{NSB}, 2}}+\cdots\right) * \mathrm{~L}_{\mathrm{f}} \\
& \mathrm{RL}_{\mathrm{NSB}, \text { total }}=\mathrm{NSB}=\alpha * \mathrm{~L}_{\mathrm{f}}
\end{aligned}
$$

By analogy with these derivations, binding to the low affinity site also can be modeled as constant ${ }^{*} \mathrm{~L}_{\mathrm{f}}$, similar to NSB, when R2 R2T. On the other hand, low-affinity specific binding behaves differently from NSB when the approximation $\mathrm{R} 2 \simeq \mathrm{R} 2 \mathrm{~T}$ fails. This approximation most likely fails as total $\left[{ }^{3} \mathrm{H}\right] \mathrm{EB}$ approaches its maximum concentration $\left(\left[{ }^{3} \mathrm{H}\right] \mathrm{EB}_{\max }\right)$ in a saturation binding experiment. In contrast and by definition, $\mathrm{R}_{\mathrm{NSB}} \simeq \mathrm{RT}_{\mathrm{NSB}}$ is valid for NSB; and NSB equals $\alpha^{*} L_{f}$ at any $\left[{ }^{3} H\right] E B_{\max }$. When $\left[{ }^{3} \mathrm{H}\right] E B_{\max }$ is sufficiently small that $\mathrm{R} 2 \simeq \mathrm{R} 2 \mathrm{~T}$ is valid for the low-affinity specific binding site, the two sites mod$\mathrm{el}_{\text {total }}$ does not fit significantly better than one sites model $_{\text {total }}$. This outcome supports the incorrect conclusion that a second low affinity site is not present. These observations led to the hypothesis that modeling total saturation binding data with ligand depletion and NSB can blur the important biological distinction between low-affinity specific binding and NSB for $\left[{ }^{3} \mathrm{H}\right] \mathrm{EB}$ and $\alpha 4 \beta 2 \mathrm{nAChR}$.

\section{Three approaches to characterizing the low-affinity specific binding site with saturation binding}

To test this hypothesis, the one site model total $_{\text {was }}$ compared to the two sites model total $_{\text {by fitting noisy total }}$ binding data from the two sites model $\mathrm{l}_{\text {free }}$ with zero NSB $(\alpha=0)$. The data (60 data points and 20 total concentrations of $\left[{ }^{3} \mathrm{H}\right] \mathrm{EB}$ ) with $\mathrm{R} 1 \mathrm{~T}=0.13 \mathrm{nM}$ and $\left[{ }^{3} \mathrm{H}\right] \mathrm{EB}_{\max }=2$ $\mathrm{nM}$ were generated with the two sites model $_{\text {free }}$ and an unrealistically large maximum signal-to-noise ratio $(\mathrm{S} / \mathrm{N})$ of $13,300\left(\mathrm{SD}=1 \times 10^{-5} \mathrm{nM}\right)$. The two sites model total fitted the data significantly better than the one site mod$\mathrm{el}_{\text {total }}\left(p\right.$ values of $1.5 \times 10^{-24}, 2.2 \times 10^{-22}$, and $1.3 \times 10^{-20}$ 


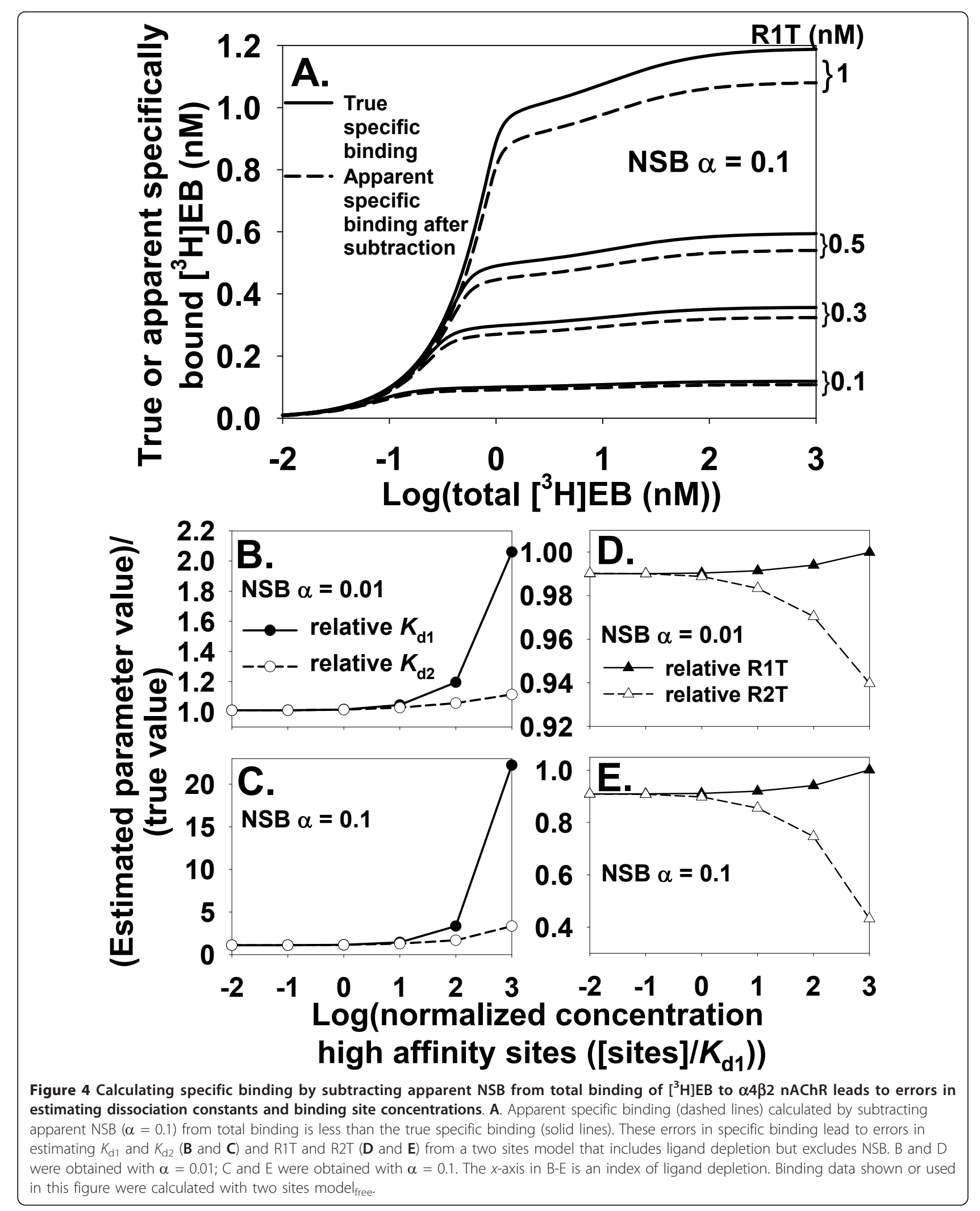


for three trials). This result showed that fitting high precision total binding data with the two models identified low-affinity specific binding.

Reducing the precision of the data was expected to make detection of binding to the low affinity site more difficult. To test this expectation, binding data with the same R1T and $\left[{ }^{3} \mathrm{H}\right] \mathrm{EB}_{\max }$ were generated with a tenfold smaller but still unrealistically large maximum $\mathrm{S} / \mathrm{N}$ of $1,330\left(\mathrm{SD}=1 \times 10^{-4} \mathrm{nM}\right)$. Under these conditions, the

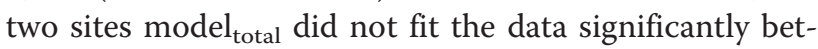

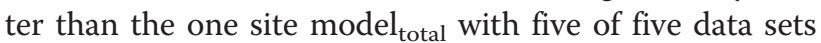
$(p=0.33,0.13,0.24,0.73$, and 1.0). Fitting noisier data led to the misleading conclusion that only one specific binding site plus NSB satisfactorily accounted for the total binding data.

How can low-affinity specific binding be distinguished more reliably from NSB as $\mathrm{S} / \mathrm{N}$ values decrease to realistic levels? Eqs. (3)-(5) suggested increasing $\left[{ }^{3} \mathrm{H}\right] \mathrm{EB}_{\max }$ so the approximation $\mathrm{R} 2 \simeq \mathrm{R} 2 \mathrm{~T}$ no longer would be valid near $\left[{ }^{3} \mathrm{H}\right] \mathrm{EB}_{\max }$. The approximation would break down because increased binding of $\left[{ }^{3} \mathrm{H}\right] \mathrm{EB}$ to $\mathrm{R} 2$ at large values of $\left[{ }^{3} \mathrm{H}\right] \mathrm{EB}$ would cause a significant decrease in $\mathrm{R} 2$ as $\left[{ }^{3} \mathrm{H}\right] \mathrm{EB}$ approaches the increased value of $\left[{ }^{3} \mathrm{H}\right] \mathrm{EB}_{\max }$. To determine whether increasing $\left[{ }^{3} \mathrm{H}\right] \mathrm{EB}_{\max }$ helped distinguish the low affinity binding site from NSB in the presence of ligand depletion, the one site model $\mathrm{t}_{\text {total }}$ and the two sites model $\mathrm{l}_{\text {total }}$ were fitted to noisy data with zero NSB and with $\left[{ }^{3} \mathrm{H}\right] \mathrm{EB}_{\max }$ increased from $2 \mathrm{nM}$ (60 data points) to $5 \mathrm{nM}$ (63 data points). The maximum $\mathrm{S} / \mathrm{N}$ of the data again was $1,330\left(\mathrm{SD}=1 \times 10^{-4} \mathrm{nM}\right)$. With $\left[{ }^{3} \mathrm{H}\right]$ $\mathrm{EB}_{\text {max }}=5 \mathrm{nM}$, the two sites model $\mathrm{l}_{\text {total }}$ fit better than the one site model $\mathrm{t}_{\text {total }}$ in five of five data sets $\left(p=4.6 \times 10^{-11}\right.$, $1.8 \times 10^{-9}, 2.8 \times 10^{-9}, 2.5 \times 10^{-9}$, and $\left.1.7 \times 10^{-12}\right)$. Increasing the data points from 60 to $63 \mathrm{did}$ not account for this improved detection of low-affinity specific binding. Instead, this result was consistent with a breakdown of the approximation $\mathrm{R} 2 \simeq \mathrm{R} 2 \mathrm{~T}$ as $\left[{ }^{3} \mathrm{H}\right] \mathrm{EB}_{\max }$ increased, leading to better discernment of binding at the low affinity site at $\left[{ }^{3} \mathrm{H}\right] \mathrm{EB}_{\max }=5 \mathrm{nM}$ compared to $2 \mathrm{nM}$.

To explore whether larger values of $\left[{ }^{3} \mathrm{H}\right] \mathrm{EB}_{\max }$ could distinguish low-affinity specific binding from NSB in data with more realistic precision, the one site model ${ }_{\text {total }}$ and two sites model $_{\text {total }}$ were fitted to noisy data (maximum S/ $\mathrm{N}=36 ; \mathrm{SD}=0.0041 \mathrm{nM})$ and zero NSB $(\alpha=0)$ (Figure $5 \mathrm{~A})$. When $\left[{ }^{3} \mathrm{H}\right] \mathrm{EB}_{\max }$ was $10 \mathrm{nM}$, the two sites model $\mathrm{l}_{\text {total }}$ usually did not fit the data better than the one site modeltotal. As $\left[{ }^{3} \mathrm{H}\right] \mathrm{EB}_{\max }$ increased, the likelihood of better fitting by the two sites model $\mathrm{l}_{\text {total }}$ and the likelihood of support for the presence of the low affinity site also increased. At $\left[{ }^{3} \mathrm{H}\right] \mathrm{EB}_{\max }=100 \mathrm{nM}$ with fitting total binding data only,

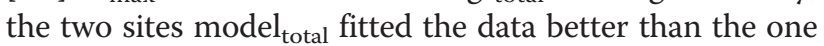
site model $_{\text {total }}$ for all trials. The increase in data points with increasing $\left[{ }^{3} \mathrm{H}\right] E B_{\max }$ did not account for this improved detection of low-affinity specific binding.

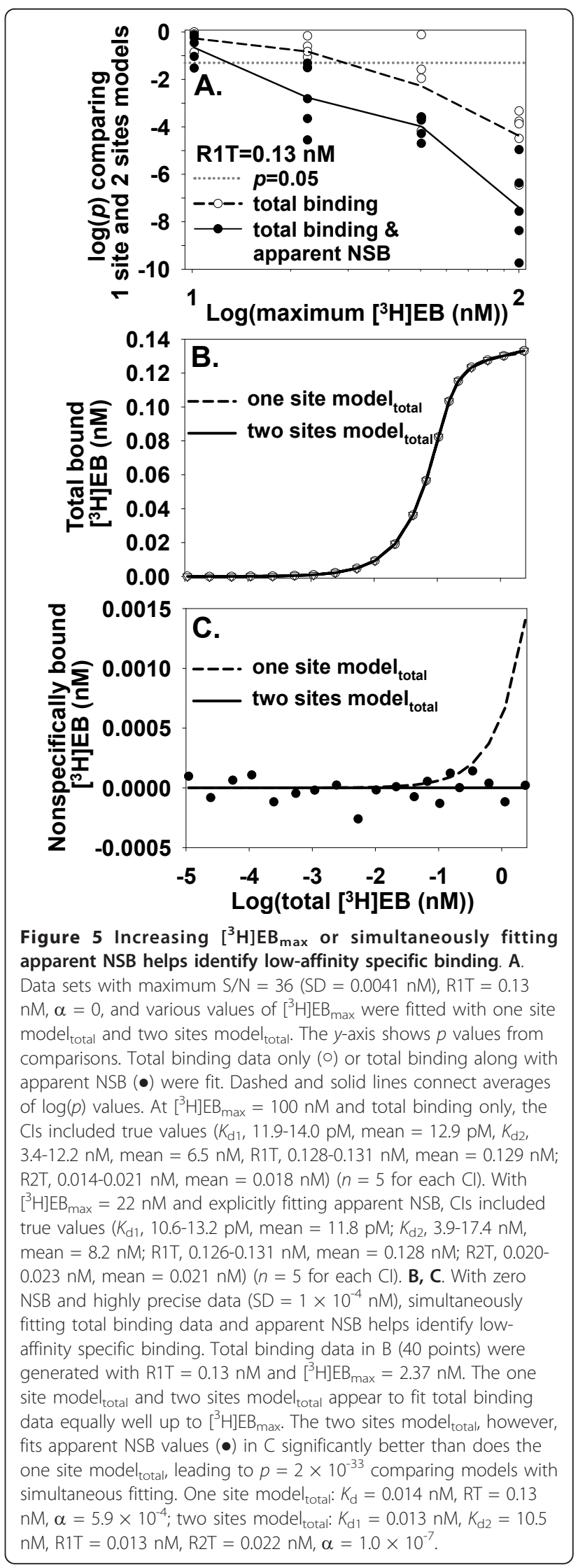


As a second potential approach, fitting apparent NSB while simultaneously fitting total binding data might help distinguish low-affinity specific binding from NSB by directly evaluating NSB. To test this hypothesis, total binding data (40 data points) and apparent NSB binding data (20 data points) were generated with the same conditions (maximum $\mathrm{S} / \mathrm{N}=1,300$; $\mathrm{SD}=1 \times 10^{-4} \mathrm{nM}$ ) that failed to distinguish the low affinity binding site with total binding data only. Simultaneously fitting total binding data (Figure 5B) and apparent NSB (Figure 5C) led to

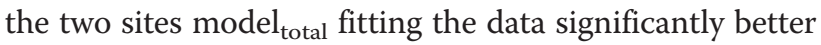
than the one site model $_{\text {total }}$ in five of five data sets. The $p$ values were vanishingly small $\left(p=6.5 \times 10^{-31}, 7.3 \times 10^{-34}\right.$, $3.2 \times 10^{-33}, 1.3 \times 10^{-28}$, and $\left.2.1 \times 10^{-33}\right)$. Figure $5 \mathrm{C}$ shows how fitting apparent NSB led to better detection of lowaffinity specific binding. The one site model $_{\text {total }}$ could not fit total binding and simultaneously accurately fit the apparent NSB. In contrast, the two sites model total $_{\text {accu- }}$ rately fit the contribution from the low affinity site to total binding and simultaneously accurately fit the apparent NSB. With more realistic precision (maximum $\mathrm{S} / \mathrm{N}=$ 36; $\mathrm{SD}=0.0041 \mathrm{nM}$ ), the two sites model $_{\text {total }}$ usually fit the data better than did the one site model $_{\text {total }}$ for $\left[{ }^{3} \mathrm{H}\right]$ $\mathrm{EB}_{\max } \geq 22 \mathrm{nM}$ (Figure 5A). In addition, simultaneously fitting both total binding and apparent NSB data more reliably identified low-affinity specific binding than did fitting only total binding. These results suggested that simultaneously fitting both total binding and apparent NSB could be superior to fitting only total binding for detecting low-affinity specific binding when NSB was negligible.

A third approach for potentially distinguishing lowaffinity specific binding from NSB is based on how NSB varies with $\alpha 4 \beta 2 \mathrm{nAChR}$ concentration. Suppose, in an idealized case, that NSB arises solely from sources (e. g., walls of a test tube, surface of a glass filter, or a constant volume of cell membranes) that are independent of $\alpha 4 \beta 2 \mathrm{nAChR}$. The independence of NSB from $\alpha 4 \beta 2$ nAChR suggests the hypothesis that varying $\alpha 4 \beta 2$ nAChR concentration helps distinguish low-affinity specific binding from NSB when ligand depletion is significant. Variation in $\alpha 4 \beta 2 \mathrm{nAChR}$ concentration could arise by injecting different amounts of cRNA into oocytes or by transfecting different amounts of cDNA into cells. To test this hypothesis, the one site model $\mathrm{t}_{\text {total }}$ and two sites model $_{\text {total }}$ with implicit fitting of NSB were fitted to noisy $\left[{ }^{3} \mathrm{H}\right] \mathrm{EB}$ binding data (maximum $\mathrm{S} / \mathrm{N}$ = 36) generated at three different concentrations of $\alpha 4 \beta 2 \mathrm{nAChR}$ and with zero NSB (Figure 6A). The two

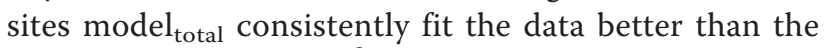
one site model $_{\text {total }}$ for $\left[{ }^{3} \mathrm{H}\right] \mathrm{EB}_{\max } \geq 22 \mathrm{nM}$ (Figure $6 \mathrm{~B}$ ). In contrast, $\left[{ }^{3} \mathrm{H}\right] \mathrm{EB}_{\max }$ in the range of $100 \mathrm{nM}$ was needed when the same numbers of data points were generated under similar conditions from a single $\alpha 4 \beta 2$
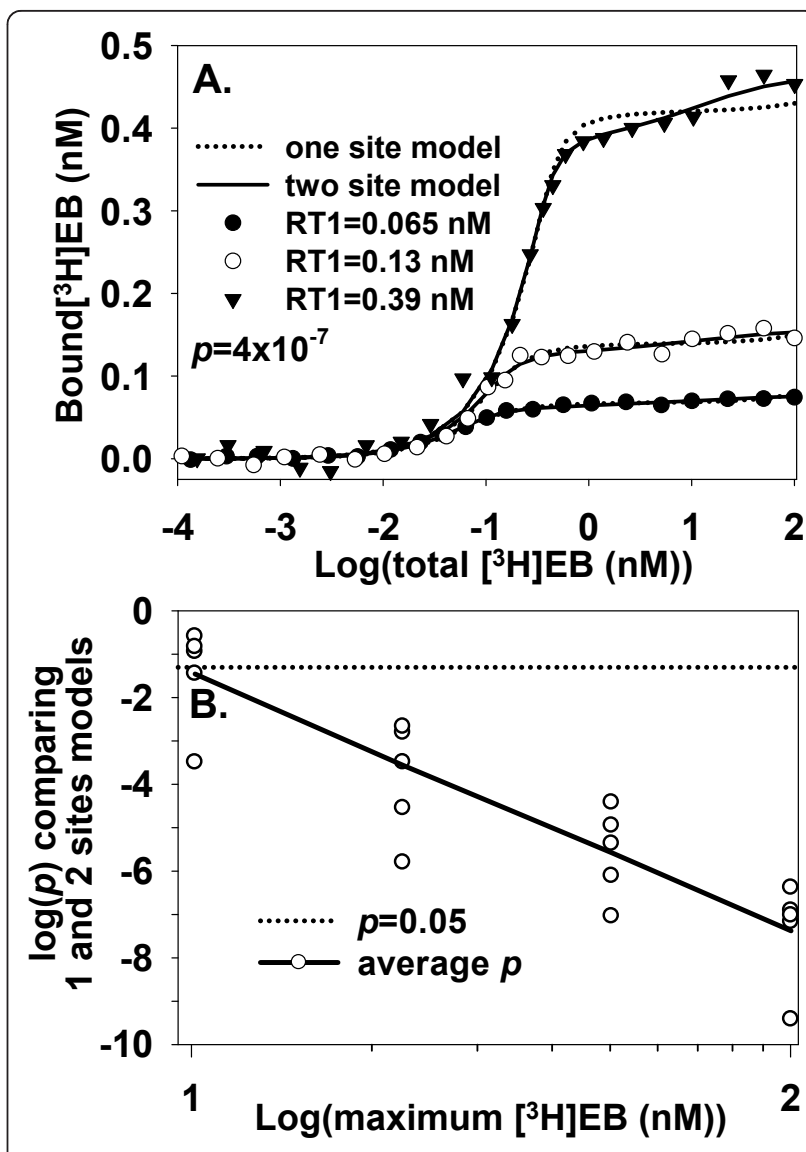

Figure 6 Simultaneously fitting binding data from several different concentrations of $\alpha 4 \beta 2$ nAChR identifies low-affinity specific binding. $\mathbf{A}$. The one site model $\left.\right|_{\text {total }}$ and two sites model $\left.\right|_{\text {total }}$ with $\left[{ }^{3} \mathrm{H}\right] \mathrm{EB}_{\max }=100 \mathrm{nM}$ were fitted to noisy binding data with R1T $=0.065,0.13$, and $0.39 \mathrm{nM}$ and $\alpha=0$. SD for noise at the R1T values was $0.002,0.004$, and 0.012 , respectively (maximum $\mathrm{S} / \mathrm{N}$ ratio $\simeq 36$ ). The two sites model $\left.\right|_{\text {total }}$ shows a significantly better fit ( $p$ $\left.=4 \times 10^{-7}\right)$. B. The $y$-axis shows $p$ values for comparisons of one site mode $\left.\right|_{\text {total }}$ and two sites model $\left.\right|_{\text {total }}$ from various $\left[^{3} \mathrm{H}\right] \mathrm{EB}_{\max }$ values. The fitted data sets are analogous to the data sets shown in $A ; p$ values from 5 data sets appear at each $x$-coordinate. Solid lines connect averages of $\log (p)$ values. The $\mathrm{Cls}$ of estimates of $K_{\mathrm{d} 1}$ (9.2$18.5 \mathrm{pM}$; mean $=13.0 \mathrm{pM})$ and $K_{\mathrm{d} 2}(1.0-1400 \mathrm{nM}$; mean $=38 \mathrm{nM})$ and R2T $(0.015-0.66$; mean $=0.34)(n=5$ for each $\mathrm{Cl})$ include true values.

nAChR concentration (Figure 5A). These results suggested that simultaneous fitting of data from various $\alpha 4 \beta 2$ nAChR concentrations, when NSB is independent of $\alpha 4 \beta 2 \mathrm{nAChR}$ concentration, could help distinguish binding to the low affinity binding site better than fitting data from a single $\alpha 4 \beta 2 \mathrm{nAChR}$ concentration.

Potentially, both sources independent of $\alpha 4 \beta 2 \mathrm{nAChR}$ concentration and sources correlated with $\alpha 4 \beta 2 \mathrm{nAChR}$ concentration might contribute significantly to NSB. The equation describing NSB in this case needs to include a component independent of $\left(R L_{N S B}\right.$, indep $)$ and a component dependent on $\alpha 4 \beta 2 \mathrm{nAChR}$ concentration 
$\left(R L_{N S B}\right.$, dep $)$. Based on Eqs. (3)-(5) and if $\mathrm{RT}_{\mathrm{NSB}}$, dep is directly proportional to $\alpha 4 \beta 2 \mathrm{nAChR}$, the relationship between NSB and free ligand becomes:

$$
\begin{aligned}
& \mathrm{RL}_{\mathrm{NSB}, \text { indep }}+\mathrm{RL}_{\mathrm{NSB}, \mathrm{dep}}=\left(\frac{\mathrm{R}_{\mathrm{NSB}, \text { indep }}}{K_{\mathrm{d}, \mathrm{NSB}, \text { indep }}}+\frac{\mathrm{R}_{\mathrm{NSB}, \text { dep }}}{K_{\mathrm{d}, \mathrm{NSB}, \mathrm{dep}}}\right) * \mathrm{~L}_{\mathrm{f}}(9) \\
& \mathrm{RL}_{\mathrm{NSB}, \text { indep }}+\mathrm{RL}_{\mathrm{NSB}, \mathrm{dep}} \cong\left(\frac{\mathrm{RT}_{\mathrm{NSB}, \text { indep }}}{K_{\mathrm{d}, \mathrm{NSB}, \text { indep }}}+\frac{\mathrm{RT}_{\mathrm{NSB}, \mathrm{dep}}}{K_{\mathrm{d}, \mathrm{NSB}, \mathrm{dep}}}\right) * \mathrm{~L}_{\mathrm{f}}(10) \\
& \mathrm{RL}_{\mathrm{NSB}, \text { indep }}+\mathrm{RL}_{\mathrm{NSB}, \mathrm{dep}} \cong\left(\frac{\mathrm{RT}_{\mathrm{NSB}, \text { indep }}}{K_{\mathrm{d}, \mathrm{NSB}, \text { indep }}}+\frac{\beta *[\alpha 4 \beta 2]}{K_{\mathrm{d}, \mathrm{NSB}, \mathrm{dep}}}\right) * \mathrm{~L}_{\mathrm{f}} \\
& \mathrm{NSB}_{\text {total }}=\mathrm{RL}_{\mathrm{NSB}, \text { indep }}+\mathrm{RL}_{\mathrm{NSB}, \text { dep }} \cong\left(\alpha_{\text {ind }}+\alpha_{\mathrm{dep}} *[\alpha 4 \beta 2]\right) * \mathrm{~L}_{\mathrm{f}}
\end{aligned}
$$

Eq. (12) for $\mathrm{NSB}_{\text {total }}$ or other expressions for $\mathrm{RT}_{\mathrm{NSB}}$, dep can be incorporated into binding equations (Figure 1) when the low affinity binding site is investigated with various $\alpha 4 \beta 2 \mathrm{nAChR}$ concentrations and binding models.

\section{Characterizing the low-affinity specific binding site by ligand depletion}

How does combining NSB with ligand depletion affect the interpretation of saturation binding with ligand depletion? Without ligand depletion, large NSB tended to overwhelm the signal from the low affinity site when total and free $\left[{ }^{3} \mathrm{H}\right] \mathrm{EB}$ were high enough to populate the low affinity binding site (Figure 3A). Conditions leading to ligand depletion, however, would increase the concentration of the low affinity site, reduce free $\left[{ }^{3} \mathrm{H}\right] \mathrm{EB}$ and NSB, and lead to relatively more binding to the low affinity site than to NSB. With $\alpha=0.1$ and $\mathrm{R} 1 \mathrm{~T}=$ $0.00013 \mathrm{nM}$ (negligible depletion), the ratio $\mathrm{R} 2 \mathrm{~L} / \mathrm{NSB}$ was $1.1 \times 10^{-5}$ at $\left[{ }^{3} \mathrm{H}\right] \mathrm{EB}=12 \mathrm{nM}$ and $4.4 \times 10^{-6}$ at $\left[{ }^{3} \mathrm{H}\right] \mathrm{EB}=50 \mathrm{nM}$. As expected, NSB overwhelmed the signal from the low affinity site at and above $\left[{ }^{3} \mathrm{H}\right] \mathrm{EB}=$ $K_{\mathrm{d} 2}$, which was the minimal concentration range needed to significantly populate the low affinity site. In contrast, with $\mathrm{R} 1 \mathrm{~T}=20 \mathrm{nM}$ (substantial depletion) and the low affinity site starting to participate in ligand depletion, the ratio $\mathrm{R} 2 \mathrm{~L} / \mathrm{NSB}$ was much larger: 3.2 at $\left[{ }^{3} \mathrm{H}\right] \mathrm{EB}=12$ $\mathrm{nM}$ and 1.0 at $\left[{ }^{3} \mathrm{H}\right] \mathrm{EB}=50 \mathrm{nM}$.

To test this promising usefulness for ligand depletion, noisy data (maximum $\mathrm{S} / \mathrm{N}=50$ at each $\mathrm{R} 1 \mathrm{~T}$ ) with $\alpha=$ 0.1 and significant ligand depletion at three values of $\mathrm{R} 1 \mathrm{~T}\left(0.13,3\right.$, and $20 \mathrm{nM} ;\left[{ }^{3} \mathrm{H}\right] \mathrm{EB}_{\max }=0.15,3.6$, and 24 $\mathrm{nM}$ ) were fitted by the one site model $_{\text {total }}$ and the two

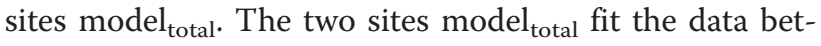
ter in ten of ten trials and produced CIs that included the true values for the parameters $\left(K_{\mathrm{d} 1}=0.0133 \mathrm{nM}, \mathrm{CI}\right.$ $=0.0120-0.0149 \mathrm{nM} ; K_{\mathrm{d} 2}=11.9 \mathrm{nM}, \mathrm{CI}=9.0-15.8 \mathrm{nM}$; fraction of low affinity site $=0.180, \mathrm{CI}=0.156-0.204 ; \alpha$
$=0.098, \mathrm{CI}=0.092-0.103)$. To test the effect of simultaneously fitting apparent NSB, noisy data (maximum S/N $=50$ ) with $\alpha=0.1$ at three values of $\mathrm{R} 1 \mathrm{~T}$ ( $0 \mathrm{nM}$ for apparent NSB alone, 0.13 , and $20 \mathrm{nM}$ ) were fitted by the one site model $_{\text {total }}$ and the two sites model total $_{\text {. The }}$ two sites model $_{\text {total }}$ fit the data better in ten of ten trials and produced CIs including the true values for the parameters $\left(K_{\mathrm{d} 1}=0.0123 \mathrm{nM}, \mathrm{CI}=0.0097-0.0156 \mathrm{nM} ; K_{\mathrm{d} 2}=\right.$ $31.8 \mathrm{nM}, \mathrm{CI}=6.5-155 \mathrm{nM}$; fraction of low affinity site $=$ 0.291, CI $=0.133-0.450 ; \alpha=0.0997, \mathrm{CI}=0.0987-0.101)$. These results suggested that increasing ligand depletion might be useful for detecting and characterizing the low affinity site when NSB is significant in saturation binding data.

\section{Effects of ligand depletion and NSB on homologous competition}

To investigate effects of ligand depletion and NSB on homologous competition, a two sites model $_{\text {free }}$ and a two sites model $_{\text {total }}$ were developed using concentration of free or total cold EB as the independent variable (Figure 1B). Calculations of total binding using the two sites model total $_{\text {to }}$ agreed with calculations with two sites model $_{\text {free }}$ to at least fourteen significant digits. The ranges of parameters tested were $1 \times 10^{-6} \mathrm{nM} \leq \mathrm{R} 1 \mathrm{~T} \leq 1 \times 10^{4} \mathrm{nM}$ and $0 \leq \alpha \leq 20$ with $1 \times 10^{-6} \mathrm{nM} \leq\left[{ }^{3} \mathrm{H}\right] \mathrm{EB}_{\text {total }} \leq 1 \times 10^{6} \mathrm{nM}$. These results confirmed the accuracy of modeling homologous competition using total cold EB concentration as the independent variable.

Increasing ligand depletion by increasing R1T changed the appearance of homologous competition data using $0.013 \mathrm{nM}\left[{ }^{3} \mathrm{H}\right] \mathrm{EB}$, which equaled the $K_{\mathrm{d}}$ for the high affinity binding site (Figure 7A). At R1T $=0.00013 \mathrm{nM}$, ligand depletion was negligible. The binding curve was symmetric about $\mathrm{IC}_{50}=0.02612 \mathrm{nM}$ with a Hill coefficient of -0.9995 . The $K_{\mathrm{d}}$ calculated from a modified Cheng-Prusoff equation for homologous competition [51], which ignores ligand depletion:

$$
\mathrm{IC}_{50}=\left[{ }^{3} \mathrm{H}\right] \mathrm{EB}+K_{\mathrm{d}}
$$

was $0.01316 \mathrm{nM}$, close to the value of $K_{\mathrm{d}}$ for the high affinity site. Increasing ligand depletion distorted the competition curve away from a sigmoidal shape and shifted the curve rightward. The curve at $\mathrm{R} 1 \mathrm{~T}=130$ $\mathrm{nM}$ was asymmetric about $\mathrm{IC}_{50}=306 \mathrm{nM}$ and did not follow Eq. (13). When $\left[{ }^{3} \mathrm{H}\right] \mathrm{EB}$ was increased to $13 \mathrm{nM}$, $\left[{ }^{3} \mathrm{H}\right]$ EB concentration controlled $\mathrm{IC}_{50}$ when ligand depletion was negligible, agreeing with Eq. (13) (Figure $7 \mathrm{~B}) . \mathrm{IC}_{50}$, therefore, remained about $13 \mathrm{nM}$ for $\mathrm{R} 1 \mathrm{~T}<$ $13 \mathrm{nM}$. Increasing ligand depletion shifted $\mathrm{IC}_{50}$ rightward when $\mathrm{R} 1 \mathrm{~T} \geq 13 \mathrm{nM}$ and made the homologous competition curves asymmetric around $\mathrm{IC}_{50}$. These 


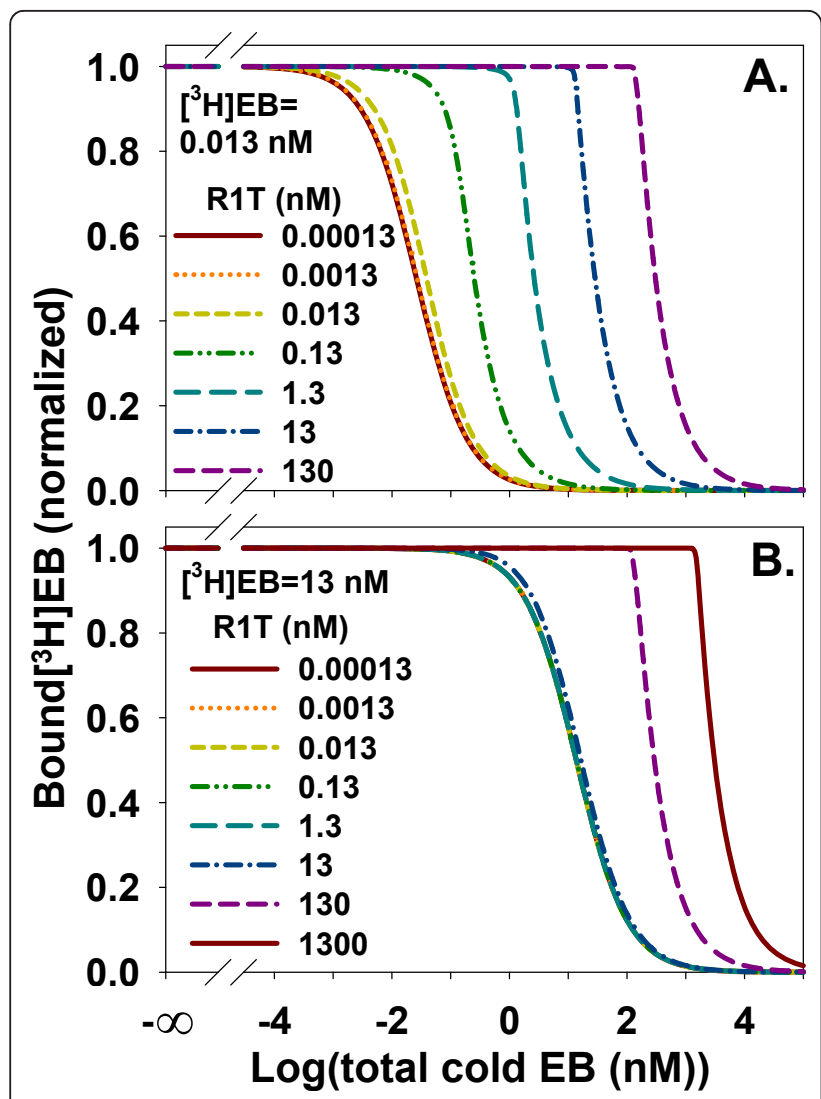

Figure 7 Ligand depletion affecting homologous competition data shifts $I_{50}$ rightward and distorts the sigmoidal shape of the competition curve. A. Homologous competition of $0.013 \mathrm{nM}$ $\left[{ }^{3} \mathrm{H}\right] \mathrm{EB}$ and $\alpha 4 \beta 2 \mathrm{nAChR}$ at various concentrations of R1T. B. Homologous competition of $13 \mathrm{nM}\left[{ }^{3} \mathrm{H}\right] \mathrm{EB}$ and $\alpha 4 \beta 2 \mathrm{nAChR}$. Compared with $\mathrm{A}$, the larger $\left[{ }^{3} \mathrm{H}\right] \mathrm{EB}$ concentration leads to an initially larger $\mathrm{IC}_{50}$ at small R1T (Eq. (13)) and a larger R1T concentration needed for the onset of significant ligand depletion. The curves for the five smallest R1T values overlap and form the leftmost solid curve. The competition curves of both A and B are distorted away from sigmoidal shape as ligand depletion increases.

results showed that increasing ligand depletion in homologous competition data shifted $\mathrm{IC}_{50}$ rightward and caused asymmetric curves around $\mathrm{IC}_{50}$.

As ligand depletion increased, its effect on binding to the high affinity site became qualitatively different from its effect on binding to the low affinity site. With negligible ligand depletion at $\mathrm{R} 1 \mathrm{~T}=0.00013 \mathrm{nM}$ and $\left[{ }^{3} \mathrm{H}\right] \mathrm{EB}=0.013$ $\mathrm{nM}$, homologous competition of $\left[{ }^{3} \mathrm{H}\right] \mathrm{EB}$ binding to the high and low affinity sites produced similarly shaped sigmoidal competition curves (Figure 8A and 8B). With substantial ligand depletion at $\mathrm{R} 1 \mathrm{~T}=130 \mathrm{nM}$ and $\left[{ }^{3} \mathrm{H}\right] \mathrm{EB}=$ $0.013 \mathrm{nM},\left[{ }^{3} \mathrm{H}\right] \mathrm{EB}$ binding to the high affinity site acquired a sharp shoulder but continued to decrease monotonically with increasing cold EB (Figure 8C). At the low affinity site, substantial ligand depletion produced an asymmetric peak of $\left[{ }^{3} \mathrm{H}\right] \mathrm{EB}$ binding (Figure $8 \mathrm{D}$ ).
Characterizing the low-affinity specific binding site with homologous competition when NSB is negligible

How well can homologous competition data with ligand depletion identify the low affinity binding site? Comparing fits from the one site model total $_{\text {and two sites model }}$ total to noisy data from a single $\left[{ }^{3} \mathrm{H}\right] \mathrm{EB}$ concentration reliably achieved this goal only with highly precise data (maximum $\mathrm{S} / \mathrm{N}=1000$ ) (Figure 9A). With $20 \mathrm{nM}\left[{ }^{3} \mathrm{H}\right] \mathrm{EB},\left[{ }^{3} \mathrm{H}\right] \mathrm{EB}$ occupied a large fraction (62\%) of the low affinity binding site when cold EB was absent. The result with $20 \mathrm{nM}\left[{ }^{3} \mathrm{H}\right]$ $\mathrm{EB}$ and $0.13 \mathrm{nM}$ R1T suggested that occupying both high and low affinity sites using one high $\left[{ }^{3} \mathrm{H}\right] \mathrm{EB}$ concentration was insufficient to identify the low affinity site when $\mathrm{S} / \mathrm{N}$ values were realistic. Figure $8 \mathrm{C}$ and $8 \mathrm{D}$, however, suggested that combining concentrations of $\left[{ }^{3} \mathrm{H}\right] \mathrm{EB}$ and binding sites on the order of $K_{\mathrm{d} 2}$ might lead to a distinctive concentration dependence of $\left[{ }^{3} \mathrm{H}\right] \mathrm{EB}$ binding that would identify the low affinity binding site with less precise data. Indeed, concentrations of $20 \mathrm{nM}\left[{ }^{3} \mathrm{H}\right] \mathrm{EB}$ and $20 \mathrm{nM}$ R1T reliably achieved this goal with less precise data (maximum $\mathrm{S} / \mathrm{N}=50$ ) (Figure 9A). These results suggested that homologous competition data from a single $\left[{ }^{3} \mathrm{H}\right] \mathrm{EB}$ concentration could identify the low affinity binding site with realistically precise data using large concentrations of $\left[{ }^{3} \mathrm{H}\right]$ EB and $\alpha 4 \beta 2$ nAChR binding sites. This approach, however, consumed large amounts of $\left[{ }^{3} \mathrm{H}\right] \mathrm{EB}$ and $\alpha 4 \beta 2$ nAChR.

Multiple concentrations of $\left[{ }^{3} \mathrm{H}\right] \mathrm{EB}$ that explored a wide range of fractional occupancies of the two binding sites might identify the low affinity binding site while consuming less $\left[{ }^{3} \mathrm{H}\right] \mathrm{EB}$ and $\alpha 4 \beta 2 \mathrm{nAChR}$. Improving the interpretation of homologous competition data from two binding sites by using several concentrations of radioligand has been described for a general case [7]. To test this method with $\left[{ }^{3} \mathrm{H}\right] \mathrm{EB}$ and $\alpha 4 \beta 2 \mathrm{nAChR}$, homologous competition data sets from $\left[{ }^{3} \mathrm{H}\right] \mathrm{EB}$ concentrations of $0.013,0.3$, and 20 $\mathrm{nM}$ and $\mathrm{R} 1 \mathrm{~T}=0.13 \mathrm{nM}$ were generated (Figure 9B-E). Multiple concentrations of $\left[{ }^{3} \mathrm{H}\right] \mathrm{EB}$ required less precise data and consumed less $\left[{ }^{3} \mathrm{H}\right] \mathrm{EB}$ and $\alpha 4 \beta 2 \mathrm{nAChR}$ to identify the low affinity site than did a single large $\left[{ }^{3} \mathrm{H}\right] \mathrm{EB}$ concentration (Figure 9A).

\section{Characterizing the low-affinity specific binding site with homologous competition when NSB is significant}

In practice, NSB is not zero and needs to be included in a model of homologous competition data. NSB, as expected, moved the baseline above zero at large concentrations of cold EB. Increasing ligand depletion shifted $\mathrm{IC}_{50}$ rightward and distorted the monotonically decreasing sigmoidal shape of the competition curve (Figure 10A). As expected from modeling of one specific binding site [19], the contribution of NSB to total $\left[{ }^{3} \mathrm{H}\right] \mathrm{EB}$ binding across the range of cold EB concentration depended on the extent of ligand depletion (Figure 10B). The dependence of NSB on ligand 


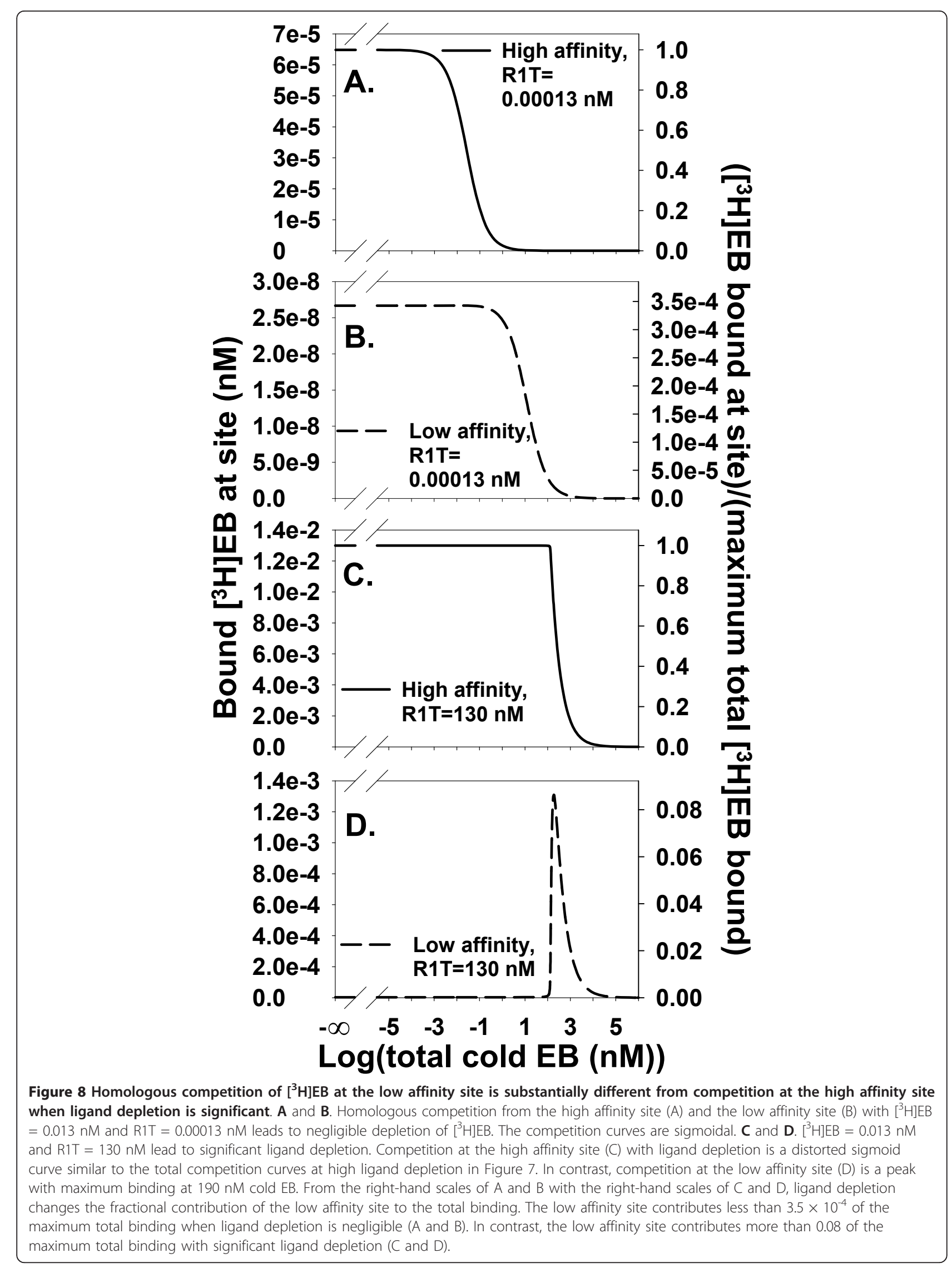




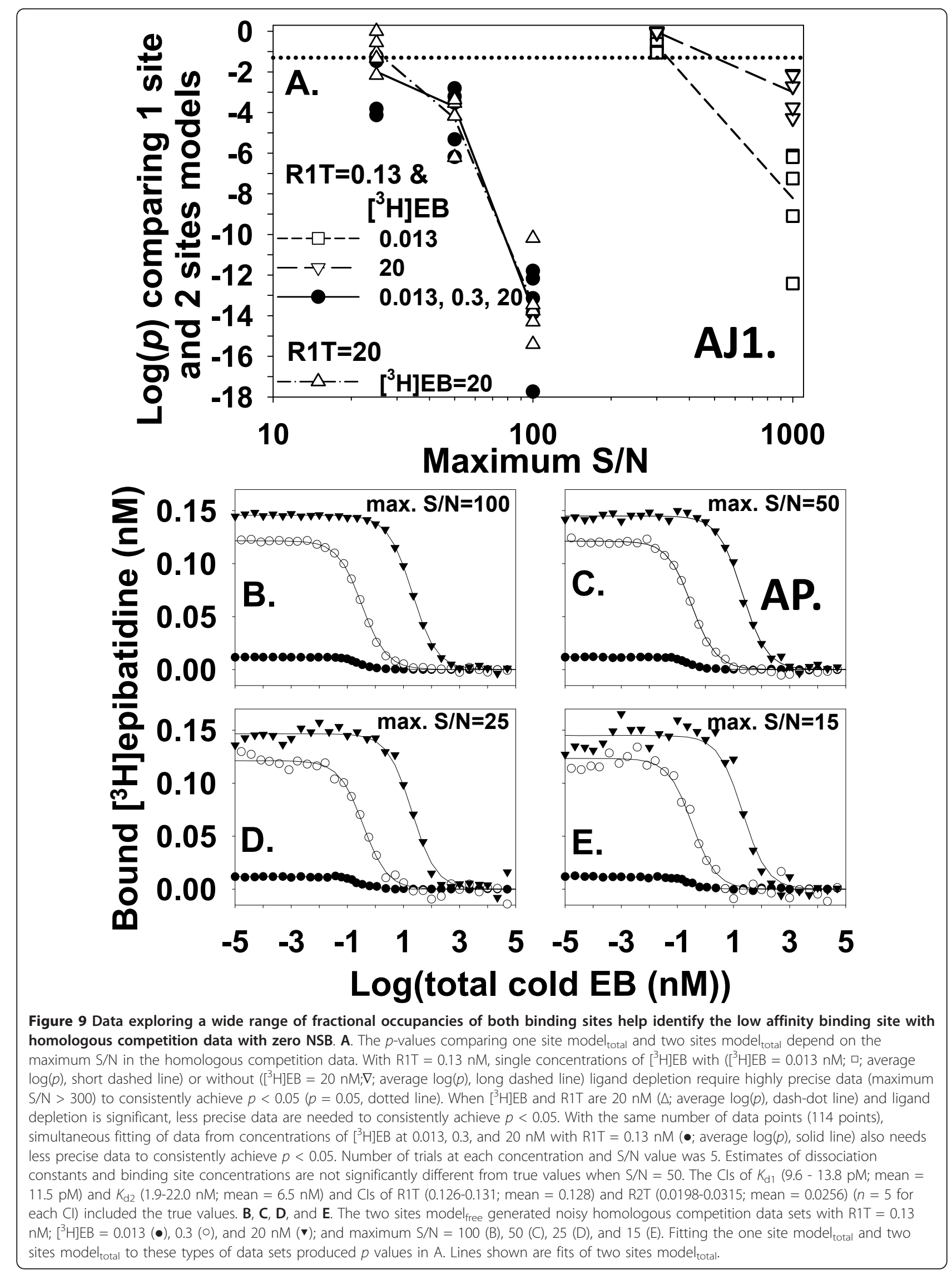




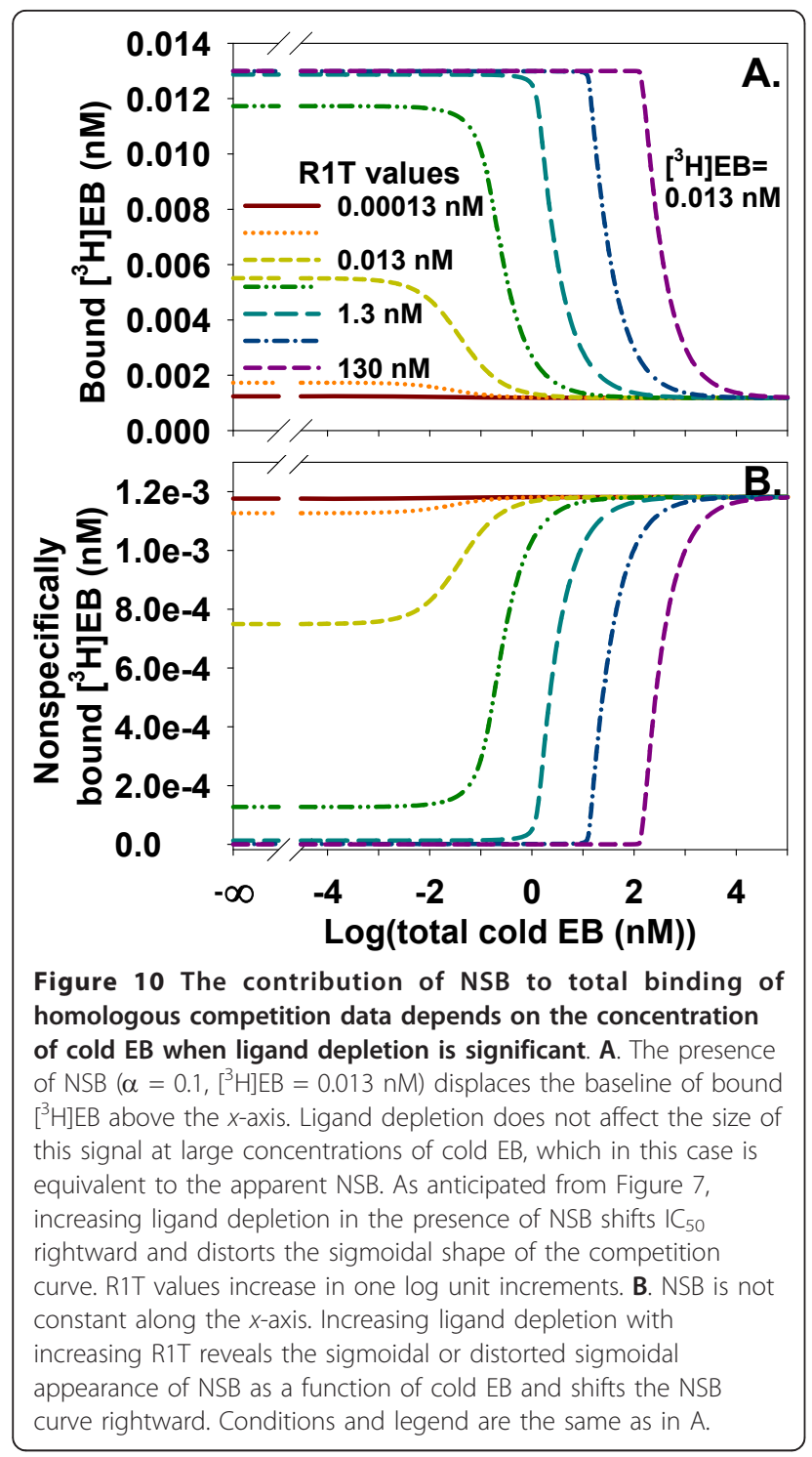

depletion showed that simply subtracting the baseline of bound $\left[{ }^{3} \mathrm{H}\right] \mathrm{EB}$ at large cold EB concentration from total bound $\left[{ }^{3} \mathrm{H}\right] \mathrm{EB}$ did not accurately calculate specifically bound $\left[{ }^{3} \mathrm{H}\right] \mathrm{EB}$. Instead, and similar to saturation binding with ligand depletion and NSB, interpreting properties of specific binding of homologous competition data with NSB needed fitting of total binding.

Homologous competition without NSB suggested simultaneously fitting data from several $\left[{ }^{3} \mathrm{H}\right] \mathrm{EB}$ concentrations at a constant concentration of $\alpha 4 \beta 2 \mathrm{nAChR}$ better identified the low affinity site than did fitting data from a single $\left[{ }^{3} \mathrm{H}\right] \mathrm{EB}$ concentration (Figure 9A). Applying this approach at $0.013,0.3$, and $20 \mathrm{nM}\left[{ }^{3} \mathrm{H}\right] \mathrm{EB}$ to homologous competition with $\mathrm{R} 1 \mathrm{~T}=0.13 \mathrm{nM}$ and $\alpha=$ 0.1 , however, revealed that NSB overwhelmed specific binding at $20 \mathrm{nM}\left[{ }^{3} \mathrm{H}\right] \mathrm{EB} .92 \%$ of total $\left[{ }^{3} \mathrm{H}\right] \mathrm{EB}$ binding was NSB, $7 \%$ was bound to the high affinity site, and only $1 \%$ was bound to the low affinity site in the absence of cold EB.

As suggested by Figures 8 and 9A, concentrations of both $\left[{ }^{3} \mathrm{H}\right] \mathrm{EB}$ and R1T on the order of $K_{\mathrm{d} 2}$ might help identify binding to the low affinity site. This method populates the low affinity site relative to the high affinity site and to NSB (Figure 11A). This method with $\left[{ }^{3} \mathrm{H}\right] \mathrm{EB}$ and R1T at $20 \mathrm{nM}$ identified binding to the low affinity site with five of five data sets at $\mathrm{S} / \mathrm{N}=50$ and three of five data sets at $\mathrm{S} / \mathrm{N}=25$ (Figure 11B). The consumption of a large concentration of $\left[{ }^{3} \mathrm{H}\right] \mathrm{EB}$ and $\alpha 4 \beta 2 \mathrm{nAChR}$ at all data points, however, was an undesirable outcome.

To reduce $\left[{ }^{3} \mathrm{H}\right] \mathrm{EB}$ and $\alpha 4 \beta 2 \mathrm{nAChR}$ consumption, both binding sites and $\left[{ }^{3} \mathrm{H}\right] \mathrm{EB}$ were varied. This method could sample a wide range of fractional occupancies of the two binding sites, which suggested a potential advantage for interpreting binding to the specific sites (Figure 11A). The maximum fractional occupancies (R1L/R1T) of the high affinity site by $\left[{ }^{3} \mathrm{H}\right] \mathrm{EB}$ were $0.089,0.29$, and 0.97 at $\left[{ }^{3}\right] \mathrm{EB}=$ $0.013,0.3$, and $20 \mathrm{nM}$ and at $\mathrm{R} 1 \mathrm{~T}=0.13,1$, and $20 \mathrm{nM}$. For the low affinity site, the maximum fractional occupancies (R2L/R2T) were 0.00081, 0.014, and 0.29. NSB made a greater fractional contribution to total binding than the low affinity site for all concentrations of cold EB when $\left[{ }^{3} \mathrm{H}\right] \mathrm{EB}=0.013 \mathrm{nM}$ and $\mathrm{R} 1 \mathrm{~T}=0.13 \mathrm{nM}$. With $\left[{ }^{3} \mathrm{H}\right] \mathrm{EB}$ and R1T at $20 \mathrm{nM}$, however, $\left[{ }^{3} \mathrm{H}\right] \mathrm{EB}$ binding by the low affinity site was greater than NSB up to $24 \mathrm{nM}$ cold EB (Figure 11A). These results suggested this method might adequately sample the contribution by the low affinity site to total binding during fitting of noisy data when NSB was significant.

The method was tested by comparing one site modeltotal and two sites model $l_{\text {total }}$ fits to noisy data from three pairs of $\left[{ }^{3} \mathrm{H}\right] \mathrm{EB}$ concentrations and binding site concentrations. The low affinity site was identified with five of five data sets with $\mathrm{S} / \mathrm{N}=50$ and four of five data sets with $\mathrm{S} / \mathrm{N}=25$ (Figure 11B). These results suggested that simultaneous fitting of homologous competition data from several concentrations of $\left[{ }^{3} \mathrm{H}\right] \mathrm{EB}$ and binding sites has the potential to identify low-affinity specific binding in the presence of NSB.

Potential misinterpretation of low-affinity specific binding as NSB in homologous competition binding

Even with highly precise data, Eqs. (3) to (5) suggested a possibility of misinterpreting low-affinity specific binding as NSB in homologous competition data when only fitting total binding data. A low affinity, second specific binding site with a large relative concentration could mimic NSB as long as $\mathrm{R} 2 \approx \mathrm{R} 2 \mathrm{~T}$ over the range of cold EB concentration. Although a large relative concentration of the second binding site was not observed from expression of $\alpha 4 \beta 2 \mathrm{nAChR}$ in oocytes [18], such a condition potentially could arise in a different heterologous 


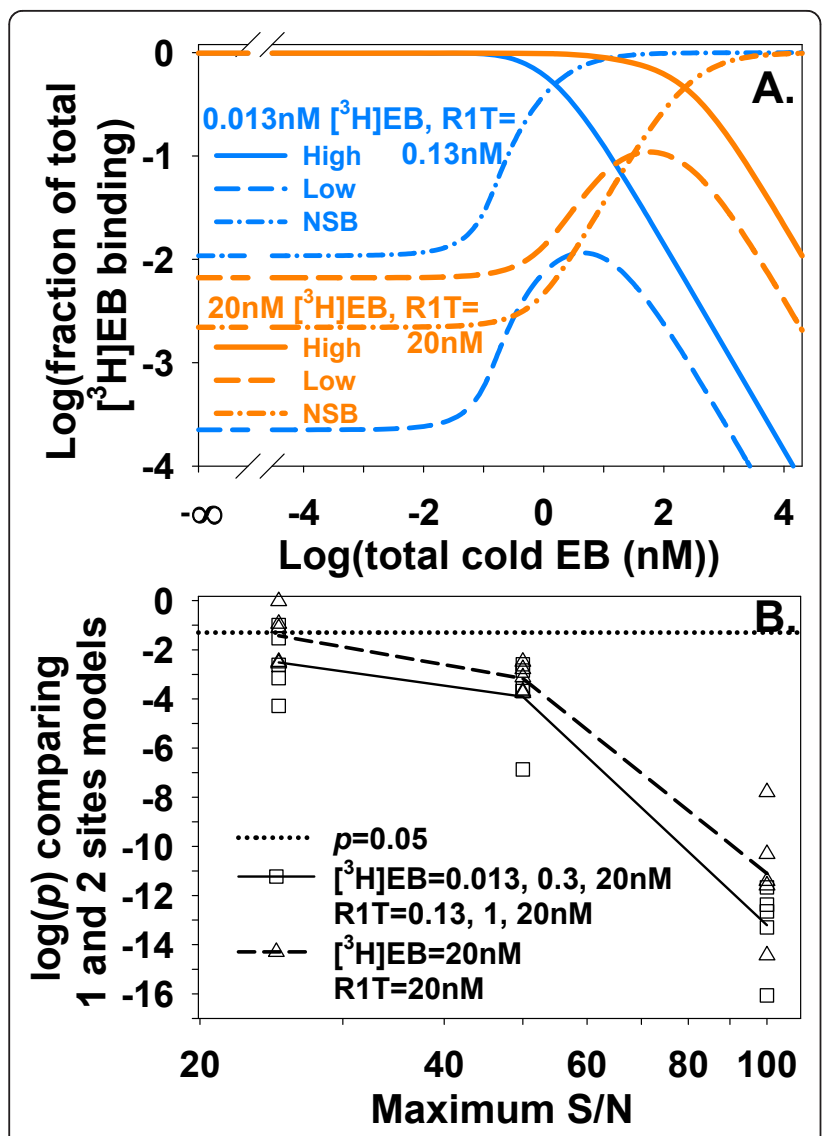

Figure 11 Ligand depletion helps identify the low affinity site when NSB is significant in competition data. A. Increasing

concentrations of binding sites and $\left[{ }^{3} \mathrm{H}\right] \mathrm{EB}$ samples a wide range of fractional contributions of the two binding sites and NSB to total binding. The combination $\left[^{3} \mathrm{H}\right] \mathrm{EB}=0.013 \mathrm{nM}$ and $\mathrm{R} 1 \mathrm{~T}=0.13 \mathrm{nM}$ mostly samples behavior of the high affinity site. The low affinity site contributes at most one-hundredth of the total binding; its contribution is always smaller than NSB. In contrast, the combination $\left[{ }^{3} \mathrm{H}\right] \mathrm{EB}=20 \mathrm{nM}$ and $\mathrm{R} 1 \mathrm{~T}=20 \mathrm{nM}$ more effectively samples behavior of the low affinity site. The low affinity site contributes a maximum of one-tenth of the total binding and contributes more than NSB does to total binding up to about 20 $n M$ cold EB. The $y$-axis values are calculated as Q/(R1L+R2L+NSB) where $Q=R 1 L, R 2 L$, or NSB. These results suggest this approach might adequately sample the contribution from the low affinity site to total binding during fitting of noisy data. $\mathbf{B}$. The $p$ values compare fits from one site model $\left.\right|_{\text {total }}$ and two sites model $\left.\right|_{\text {total }}$ to competition data generated with $\alpha=0.1$. One set $(\Delta)$ used $\left[{ }^{3} \mathrm{H}\right] \mathrm{EB}=$ $\mathrm{R} 1 \mathrm{~T}=20 \mathrm{nM}$; the second set $\left.(\square),{ }^{3} \mathrm{H}\right] \mathrm{EB}=0.013,0.3$, and $20 \mathrm{nM}$ and $\mathrm{R} 1 \mathrm{~T}=0.13,1$, and $20 \mathrm{nM}$. Lines show average $\log (p)$. At $\mathrm{S} / \mathrm{N}=50$ for the first set, $\mathrm{Cl}$ included the true values $\left(K_{\mathrm{d} 1}=0.016 \mathrm{nM}(\mathrm{Cl}\right.$ : 0.010-0.025 nM); $K_{\mathrm{d} 2}=14.9 \mathrm{nM}(\mathrm{Cl}: 6.3-35 \mathrm{nM}) ; \mathrm{R} 1 \mathrm{~T}=20.2 \mathrm{nM}(\mathrm{Cl}:$ 19.7-20.6 nM); R2T $=4.7 \mathrm{nM}(\mathrm{Cl}: 2.8-6.6 \mathrm{nM}) ; \alpha=0.096$ (Cl: 0.091$0.100)(n=5$ for each $\mathrm{Cl})$. At $\mathrm{S} / \mathrm{N}=25$ for the second set, $\mathrm{Cls}$ included the true values $\left(K_{\mathrm{d} 1}=0.012 \mathrm{nM}(\mathrm{Cl}: 0.009-0.014 \mathrm{nM}) ; K_{\mathrm{d} 2}=\right.$ $17.0 \mathrm{nM}(\mathrm{Cl}: 4.3-66 \mathrm{nM})$; fraction of R2T $=0.28$ (Cl: 0.11-0.45); $\alpha=$ 0.10 (Cl: 0.093-0.108) expression system. The potential for confusing low-affinity specific binding and NSB was explored by comparing homologous competition data from a one site model $_{\text {free }}$ with $\alpha=0.2$ with data from a two sites modelfree with $\alpha=0$ and $K_{\mathrm{d} 2}=\mathrm{R} 2 \mathrm{~T} / 0.2$. As R2T and $K_{\mathrm{d} 2}$ increased, the upper limit of cold EB concentration for which R2 R2T remained valid also increased. The data

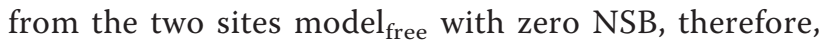
displayed increasingly long plateaus mimicking NSB at large concentrations of cold EB. The long plateaus, however, arose from specific binding to the low affinity $\alpha 4 \beta 2 \mathrm{nAChR}$ binding site and not from NSB. Figure $12 \mathrm{~A}$ suggested that homologous competition data at a single $\left[{ }^{3} \mathrm{H}\right] \mathrm{EB}$ concentration might not distinguish binding to a low affinity site from NSB unless either the maximum concentration of cold EB exceeded $K_{\mathrm{d} 2}$ or NSB was measured without $\alpha 4 \beta 2 \mathrm{nAChR}$.

Heterologous competition with ligand depletion and NSB Homologous competition is a specific case of the more general case of heterologous competition, for which the dissociation constants of the radioligand and the heterologous competitor differ. For heterologous competition, identification of a low affinity site and estimates for dissociation constants for $\left[{ }^{3} \mathrm{H}\right] \mathrm{EB}$ to high and low affinity sites typically are determined from saturation binding. In this case, inhibition constants $\left(K_{\mathrm{i} 1}\right.$ and $K_{\mathrm{i} 2}$ in Figure 1 ) for the competitor and the concentration of binding sites are the only unknowns when fitting heterologous displacement data. This study focuses on how ligand depletion and NSB affects heterologous competition with high and low affinity binding sites of $\left[{ }^{3} \mathrm{H}\right] \mathrm{EB}$. In addition, this study investigates concentrations of $\left[{ }^{3} \mathrm{H}\right]$ $\mathrm{EB}$ and $\alpha 4 \beta 2 \mathrm{nAChR}$ that might facilitate studying the low affinity site.

To determine how ligand depletion without NSB affects heterologous competition with $\left[{ }^{3} \mathrm{H}\right] \mathrm{EB}$ and $\alpha 4 \beta 2$ nAChR, competition data at increasing concentrations of binding sites were generated with nicotine as the competitor. The dissociation constants for nicotine were $0.84 \mathrm{nM}$ for the high affinity site [18] and $775 \mathrm{nM}$ for the low affinity site. The inhibition constant for nicotine at the low affinity site was assigned so that $K_{\mathrm{i} 2} / K_{\mathrm{i} 1}$ for nicotine $=K_{\mathrm{d} 2} / K_{\mathrm{d} 1}$ for EB. When ligand depletion was negligible, $\mathrm{IC}_{50}$ values varied only slightly with binding site concentration (Figure 13A-F). The $K_{\mathrm{i}}$ values derived from these $\mathrm{IC}_{50}$ values and the Cheng-Prusoff equation (Eq. (14)),

$$
\mathrm{IC}_{50}=\left[{ }^{3} \mathrm{H}\right] \text { epibatidine }+K_{\mathrm{i}}
$$




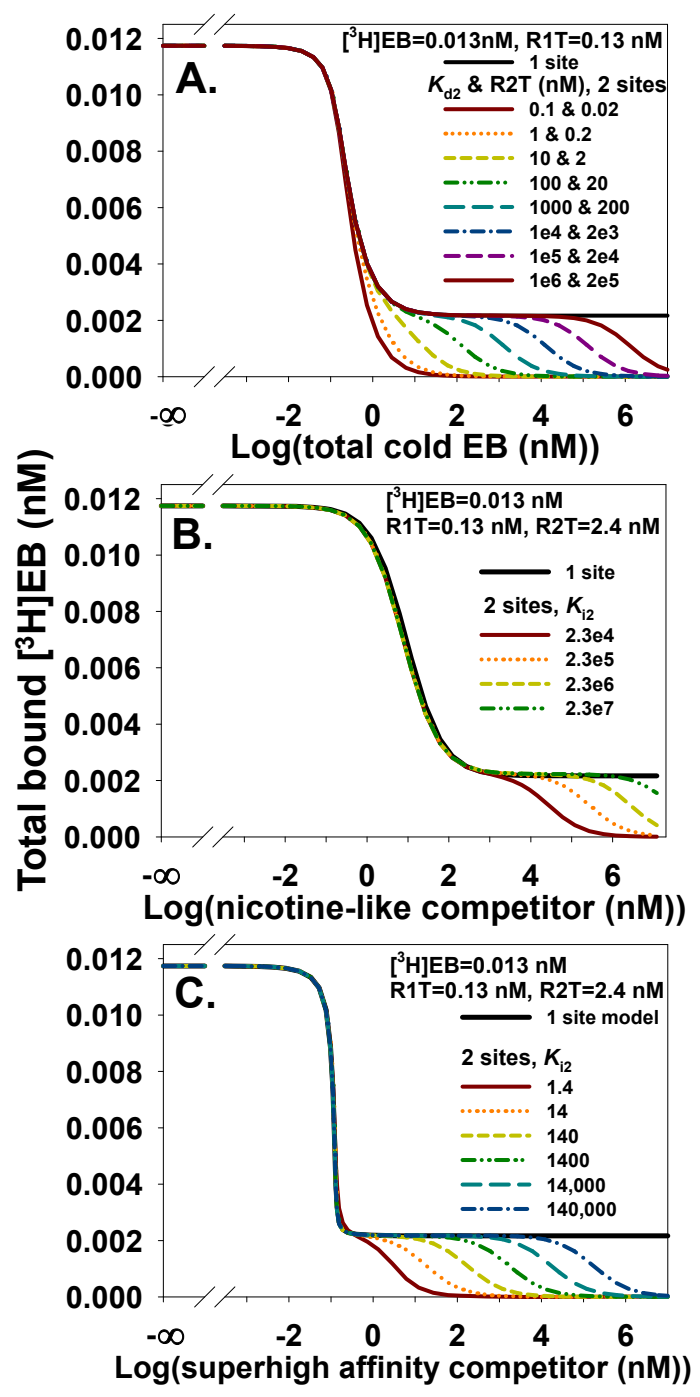

Figure 12 Binding to a low affinity second binding site with hypothetically large R2T and $K_{\mathrm{d} 2}$ or $K_{\mathrm{i} 2}$ values mimic NSB in homologous and heterologous competition data. A. The one site model free $(\alpha=0.2)$ and two sites model free $(\alpha=0)$ generated homologous competition data with $K_{\mathrm{d} 2}=\mathrm{R} 2 \mathrm{~T} / 0.2$. With increasing R2T and $K_{\mathrm{d} 2}$, the two sites model $\left.\right|_{\text {free }}$ produces increasingly long plateaus of total bound $\left.{ }^{3} \mathrm{H}\right] \mathrm{EB}$, similar to NSB. Low-affinity specific binding is distinguished from NSB only when cold EB concentration exceeds $K_{\mathrm{d} 2}$. $\mathbf{B}$. Heterologous competition of [ $\left.{ }^{3} \mathrm{H}\right] \mathrm{EB}$ with a nicotinelike competitor at a low affinity site can mimic NSB. The one site model $_{\text {free }}$ with $\alpha=0.2$ generated heterologous competition data with $K_{\mathrm{i} 1}=0.84 \mathrm{nM}$ for the competitor (value for nicotine [18]). With these values and R2T $=2.4 \mathrm{nM}$ and $\alpha=0$, the two sites model $\left.\right|_{\text {total }}$ fits these data well up to a competitor concentration of $K_{\mathrm{i} 2}$. Lowaffinity specific binding is distinguished from NSB only when the competitor concentration exceeds $K_{\mathrm{i} 2}$. $\mathrm{C}$. With a superhigh affinity competitor, increasing R2T and varying $K_{\mathrm{i} 2}$ with heterologous competition of $\left[{ }^{3} \mathrm{H}\right] \mathrm{EB}$ at a low affinity site can mimic NSB. The one site model $\left.\right|_{\text {free }}$ with $\alpha=0.2$ generated heterologous competition data with $K_{\mathrm{i} 1}=1.3 \times 10^{-4} \mathrm{nM}$. With $\alpha=0$, the two sites model ${ }_{\text {total }}$ fits well to these data up to a competitor concentration of $K_{\mathrm{i} 2}$. Lowaffinity specific binding is distinguished from NSB only when competitor concentration exceeds $K_{i 2}$. which assumes a single binding site without ligand depletion, were close to $K_{\mathrm{i} 1}$ for nicotine $(0.90,0.87$, and $0.96 \mathrm{nM}$ at $0.013,0.3$, and $20 \mathrm{nM}\left[{ }^{3} \mathrm{H}\right] \mathrm{EB}$ and $\mathrm{R} 1 \mathrm{~T}=$ $0.00013 \mathrm{nM})$. As increasing ligand depletion shifted $\mathrm{IC}_{50}$ rightward (Figure 13A-F), the estimate of $K_{\mathrm{i}}$ from the Cheng-Prusoff equation no longer closely matched $K_{\mathrm{i} 1}$ for nicotine. The shape of the competition curve remained approximately sigmoidal with a Hill coefficient consistently near -1 at all levels of ligand depletion.

Although nicotine binds more weakly than $\left[{ }^{3} \mathrm{H}\right] \mathrm{EB}$ to $\alpha 4 \beta 2 \mathrm{nAChR}$, other ligands developed in the future, especially derivatives of $\mathrm{EB}$, conceivably might bind more tightly than $\left[{ }^{3} \mathrm{H}\right] \mathrm{EB}$. To determine how ligand depletion affects heterologous competition with a superhigh affinity competitor, heterologous competition data were generated with two dissociation constants 100-fold tighter $\left(1.3 \times 10^{-4}\right.$ and $\left.0.12 \mathrm{nM}\right)$ than the two dissociation constants for $\left[{ }^{3} \mathrm{H}\right] \mathrm{EB}$. When ligand depletion of $\left[{ }^{3} \mathrm{H}\right] \mathrm{EB}$ was negligible, $\mathrm{IC}_{50}$ values were independent of binding site concentration and led to slightly high estimates of $K_{\mathrm{i} 1}\left(1.4 \times 10^{-4} \mathrm{nM}\right)$ using Eq. (14); Hill coefficients were about -1 (Figure 13G-L). Increasing ligand depletion shifted $\mathrm{IC}_{50}$ rightward and, in contrast to nicotine, shifted Hill coefficients to strongly negative values (for example, -35 with $\left[{ }^{3} \mathrm{H}\right] \mathrm{EB}=0.013 \mathrm{nM}$ and $\mathrm{R} 1 \mathrm{~T}=130 \mathrm{nM})$. These results showed the effect of ligand depletion on the Hill coefficient depended markedly on whether the competitor bound more tightly or less tightly than $\left[{ }^{3} \mathrm{H}\right] \mathrm{EB}$.

$K_{\mathrm{i} 2}$ for a competitor potentially can be estimated with procedures analogous to procedures investigated for homologous competition. To test the approach described in Figures 9 and 11 for homologous competition, noisy heterologous competition data for nicotine and $\left[{ }^{3} \mathrm{H}\right] \mathrm{EB}$ with ligand depletion and NSB were fit with the two sites $_{\text {total }}$ model (Figure 14). A single $0.013 \mathrm{nM}$ concentration of $\left[{ }^{3} \mathrm{H}\right] \mathrm{EB}$ with $\mathrm{R} 1 \mathrm{~T}=0.13 \mathrm{nM}$ did not significantly populate the low affinity site (Figure 14A). That concentration combination produced reliable estimates of $K_{\mathrm{i} 2}$ only with highly precise data (maximum $\mathrm{S} / \mathrm{N} \geq 1000$ ) (Figure $14 \mathrm{C}$ ). At maximum $\mathrm{S} / \mathrm{N}=100$, fits with competition by nicotine at the high and low affinity sites generally were not significantly better than fits with competition by nicotine at only the high affinity site $(p>$ 0.05 for six of six trials). Similar to the findings in Figures 9 and 11, increasing ligand depletion and populating both the high and low affinity sites with larger concentrations of $\left[{ }^{3} \mathrm{H}\right] \mathrm{EB}$ and $\alpha 4 \beta 2 \mathrm{nAChR}$ (Figure 14B) allowed more reliable estimates of $K_{\mathrm{i} 2}$ with less precise data (Figure 14C). At maximum $\mathrm{S} / \mathrm{N}=15$ with this approach, fits with competition by nicotine at the two $\left[{ }^{3} \mathrm{H}\right] \mathrm{EB}$ binding sites generally were significantly better than fits with competition by nicotine at only the high affinity site $\left(0.007<p<5 \times 10^{-10}\right.$ for six of six trials). These results 


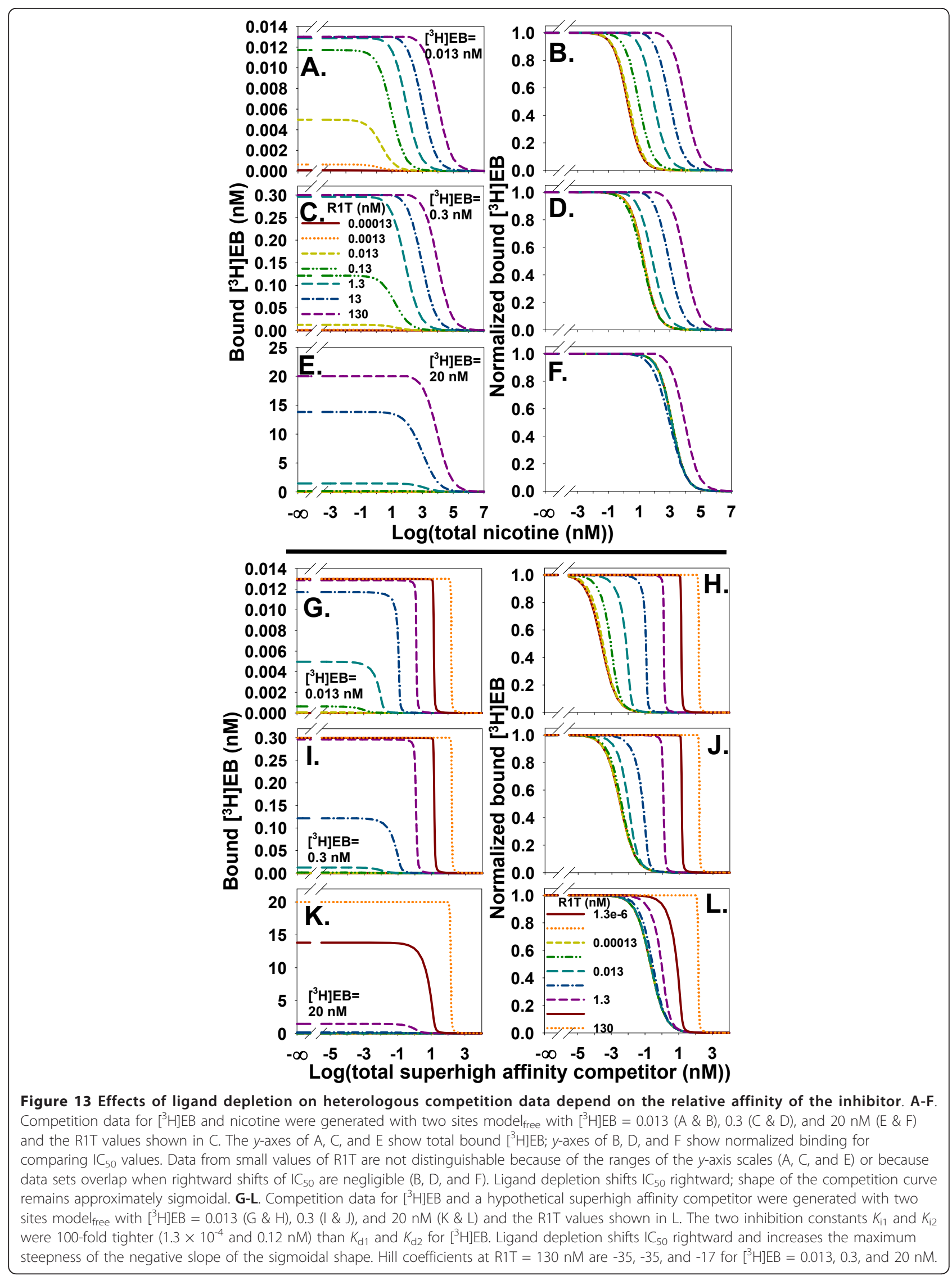



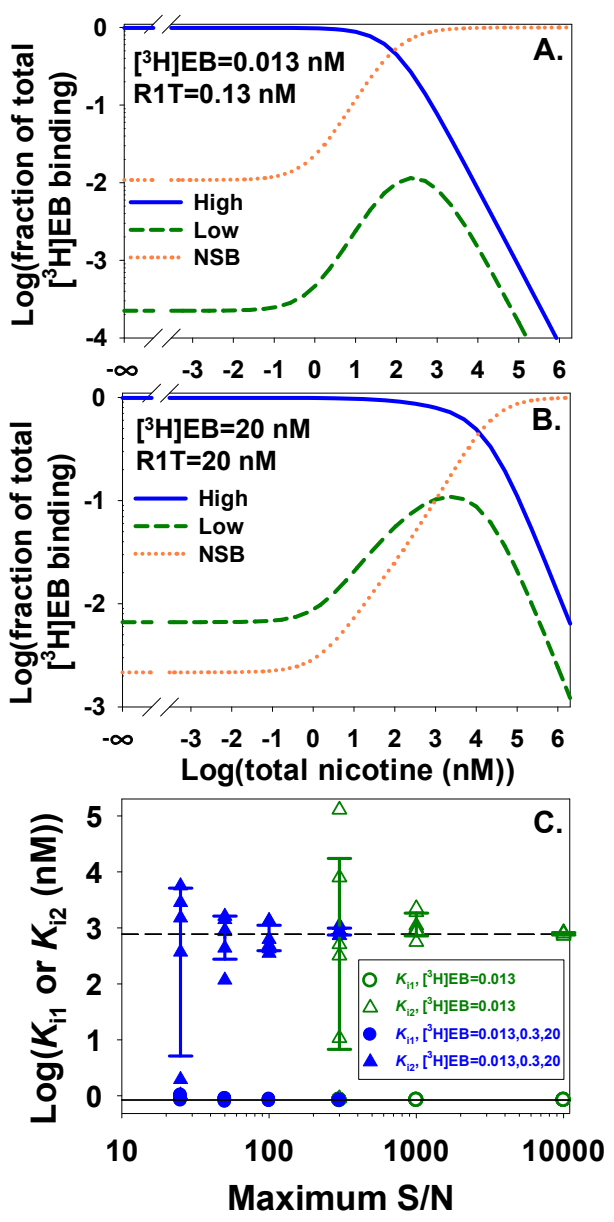

Figure 14 Ligand depletion improves precision of estimated $K_{\mathrm{i} 2}$ for nicotine with noisy data and NSB. Ligand depletion improves precision of estimated $K_{\mathrm{i} 2}$ for nicotine with noisy data. A and $\mathbf{B}$. Increasing concentrations of binding sites and $\left[{ }^{3} \mathrm{H}\right] \mathrm{EB}$ samples a wide range of fractional contributions of the two binding sites and NSB to total $\left.{ }^{3} \mathrm{H}\right] \mathrm{EB}$ binding as nicotine concentration varies. In $A$, the combination $\left.{ }^{3} \mathrm{H}\right] \mathrm{EB}=0.013 \mathrm{nM}$ and $\mathrm{R} 1 \mathrm{~T}=0.13 \mathrm{nM}$ predominantly samples interaction between $\left[^{3} \mathrm{H}\right] \mathrm{EB}$ and nicotine at the high affinity site. In $\mathrm{B}$, the combination $\left.{ }^{3} \mathrm{H}\right] \mathrm{EB}=20 \mathrm{nM}$ and R1T $=20 \mathrm{nM}$ with substantial ligand depletion more effectively samples interaction between $\left[{ }^{3} \mathrm{H}\right] \mathrm{EB}$ and nicotine at the low affinity site. The low affinity site contributes a maximum of one-tenth of total $\left.{ }^{3} \mathrm{H}\right] \mathrm{EB}$ binding and contributes more than NSB does to total $\left[{ }^{3} \mathrm{H}\right] \mathrm{EB}$ binding up to about $1000 \mathrm{nM}$ nicotine. The $y$-axis values were calculated as $\mathrm{Q} /(\mathrm{R} 1 \mathrm{~L}+\mathrm{R} 2 \mathrm{~L}+\mathrm{NSB})$ where $\mathrm{Q}=\mathrm{R} 1 \mathrm{~L}$, R2L, or NSB. C. Noisy heterologous competition data for $\left[{ }^{3} \mathrm{H}\right] \mathrm{EB}$ and nicotine with various maximum $\mathrm{S} / \mathrm{N}$ were fit with two sites total model to estimate $K_{\mathrm{i} 1}$ and $K_{\mathrm{i} 2}$. The $K_{\mathrm{i} 2}$ estimates shown with green $\Delta$ were derived with $\mathrm{R} 1 \mathrm{~T}=0.13 \mathrm{nM}$. Modest ligand depletion and negligible occupancy by $\left[{ }^{3} \mathrm{H}\right] \mathrm{EB}$ of the low affinity binding site lead to low precision of $K_{\mathrm{i} 2}$ estimates at maximum $\mathrm{S} / \mathrm{N}=300 . K_{\mathrm{i} 2}$ estimates shown with blue $\boldsymbol{\Delta}$ were derived with $\mathrm{R} 1 \mathrm{~T}=0.13,1,20 \mathrm{nM}$. Increasing ligand depletion and occupancy of the low affinity site by $\left[{ }^{3} \mathrm{H}\right] \mathrm{EB}$ lead to more precise $K_{\mathrm{i} 2}$ estimates with noisier data. Error bars show standard deviations. $K_{\mathrm{i} 1}$ estimates (green $\circ$ or blue $\bullet$ ) are relatively independent of maximum $\mathrm{S} / \mathrm{N}$ values. The number of data points (114 points) was identical in the two sets of estimates. Solid line: true $K_{\mathrm{i} 1}(0.84 \mathrm{nM})$; dashed line: true $K_{\mathrm{i} 2}(775 \mathrm{nM}) ; \alpha_{\mathrm{L}}=0.1 ; \alpha_{B}=0$. suggest that fitting data with large ligand depletion might identify the presence of nicotine competition at the low affinity site even if those data have a low $\mathrm{S} / \mathrm{N}$ and an estimate of $K_{\mathrm{i} 2}$ has low precision.

Similar to homologous competition data (Figure 12A), low-affinity specific binding might be misinterpreted as NSB when fitting heterologous competition data with a model of total binding. To investigate this possibility with a nicotine-like inhibitor $\left(K_{\mathrm{i} 1}=0.84 \mathrm{nM}\right)$, heterologous depletion data from the one site model $_{\text {free }}$ with NSB $(\alpha=$ $0.2)$ were compared to data from the two sites model $_{\text {total }}$ without NSB. With R2T $=2.4 \mathrm{nM}$ and various values of $K_{\mathrm{i} 2}$, the two sites model $_{\text {total }}$ produced a long plateau mimicking NSB (Figure 12B). The value of $K_{\mathrm{i} 2}$ at this constant value of R2T determined the length of the plateau along the $x$-axis. One log unit increase of the value of $K_{\mathrm{i} 2}$ lengthened the plateau of binding to the low affinity site by one log unit. A competitor binding more tightly than $\left[{ }^{3} \mathrm{H}\right] \mathrm{EB}$ to the high affinity binding site produced similar results (Figure 12C). These results suggested that binding to the low affinity site might be identified as NSB at a single $\left[{ }^{3} \mathrm{H}\right] \mathrm{EB}$ concentration unless either the maximum competitor concentration was greater than $K_{\mathrm{i} 2}$ or NSB was measured without $\alpha 4 \beta 2 \mathrm{nAChR}$.

\section{Characterizing high and low affinity binding sites when NSB of a heterologous competitor is unknown}

The NSB of an unlabeled competitor is not measured by heterologous competition measurements and often is assumed to be zero. The true value of $\alpha_{\text {competitor }}$, therefore, presents a source of uncertainty about values of inhibition constants. This uncertainty was investigated by increasing

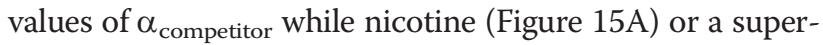
high affinity competitor (Figure $15 \mathrm{C}$ ) inhibited binding of $\left[{ }^{3} \mathrm{H}\right] \mathrm{EB}$ to $\alpha 4 \beta 2 \mathrm{nAChR}$. As the true value of $\alpha_{\text {competitor }}$ for nicotine increased, apparent values of $K_{\mathrm{i} 1}\left(K_{\mathrm{i} 1 \text {, app }}\right)$ and $K_{\mathrm{i} 2}$ $\left(K_{\mathrm{i} 2 \text {, app }}\right)$ also increased (Figure $\left.15 \mathrm{~B}\right)$. The contours of competition curves with the superhigh affinity competitor

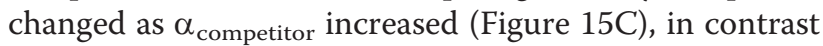
to the constant contours with nicotine. The ratio $K_{\mathrm{i} 2 \text {, app }} /$ $K_{\mathrm{i} 1 \text {, app }}$ for the superhigh affinity competitor, however, was

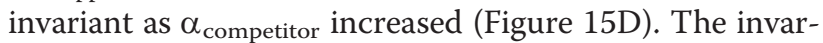
iance of $K_{\mathrm{i} 2 \text {, app }} / K_{\mathrm{i} 1 \text {, app }}$ at the two binding sites of $\alpha 4 \beta 2$ $\mathrm{nAChR}$ is important because the ratio represents the difference in free energy of binding at the two binding sites. This difference reflects differences in the interactions between the competitor and binding sites and structural differences between the high and low affinity binding sites. This measured free energy difference is independent of $\alpha_{\text {competitor }}$.

\section{Discussion}

A model that fits total binding data as a function of total ligand can correctly interpret those data when 

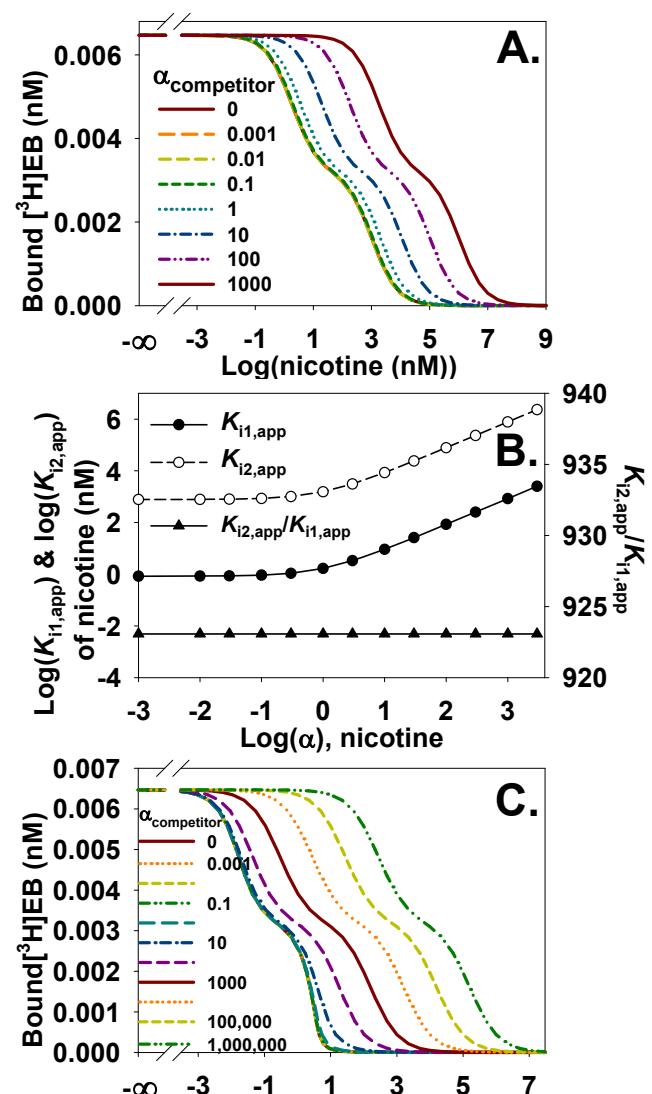

Log(superhigh affinity competitor (nM))

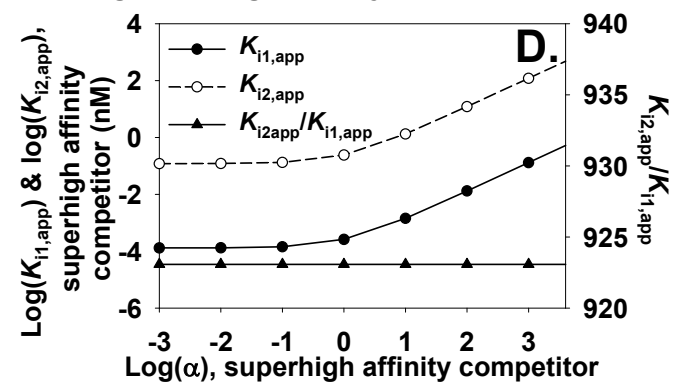

Figure 15 NSB of a competitor changes $K_{\mathrm{i} 1}$, app and $K_{\mathrm{i} 2}$, app but not $K_{\mathrm{i} 2 \text {, app }} / K_{\mathrm{i} 1 \text {, app. }}$ A. The two sites model free generated competition data for $\left[^{3} \mathrm{H}\right] \mathrm{EB}$ and nicotine with R1T $=0.013 \mathrm{nM}$ and $\mathrm{R} 2 \mathrm{~T}=3.9 \mathrm{nM}$ so the competition curve clearly shows the two binding sites. Increasing $\alpha_{\text {competitor }}$ shifted the curve rightward without changing the shape of the curve. B. To determine how increasing $\alpha_{\text {competitor }}$ affected apparent values of $K_{\mathrm{i} 1}\left(K_{\mathrm{i} 1}\right.$, app $)$ and $K_{\mathrm{i} 2}$ $\left(K_{i 2, \text { app }}\right)$ with $\alpha_{\text {competitor, app }}=0$, two sites model $\left.\right|_{\text {total }}$ was fitted to the competition curves in A. The only degrees of freedom for this fitting were $K_{\mathrm{i} 1}$, app and $K_{\mathrm{i} 2}$, app for nicotine. Increasing $\alpha_{\text {competitor }}$ increases $K_{\mathrm{i} 1}$, app and $K_{\mathrm{i} 2}$, app but does not change $K_{\mathrm{i} 2}$, app $K_{\mathrm{i} 1 \text {, app }}$ a ratio reflecting the difference in free energy of nicotine binding at the two sites. $\mathbf{C}$. Similar to $\mathbf{A}$, the two sites model $\left.\right|_{\text {free }}$ generated competition data for $\left[^{3} \mathrm{H}\right] \mathrm{EB}$ and a superhigh affinity competitor with R1T $=0.013 \mathrm{nM}, \mathrm{R} 2 \mathrm{~T}=3.9 \mathrm{nM}, K_{\mathrm{i} 1}=0.00013 \mathrm{nM}$, and $K_{\mathrm{i} 2}=$ $0.12 \mathrm{nM}$. The curves clearly show the two binding sites. In contrast to $A$, shapes of the competition curves change as increasing

$\alpha_{\text {competitor }}$ shifts the curve rightward. D. Similar to nicotine, $K_{\mathrm{i} 2 \text {, app } /}$ $K_{\mathrm{i1}}$, app for the superhigh affinity competitor does not vary with

$\alpha_{\text {competitor. }}$ ligand depletion and NSB are significant [19]. This approach is straightforward with one binding site. This study shows that the approach for $\left[{ }^{3} \mathrm{H}\right] \mathrm{EB}, \alpha 4 \beta 2$ $\mathrm{nAChR}$, and two binding sites needs modifications for identifying binding to the low affinity site. In particular, identifying the low affinity site can be challenging because of phenomenological and computational similarities between low-affinity specific binding and NSB.

This study is novel because it shows that fitting total binding data from $\left[{ }^{3} \mathrm{H}\right] \mathrm{EB}$ and $\alpha 4 \beta 2 \mathrm{nAChR}$ might be insufficient for characterizing the low affinity site when ligand depletion and NSB are significant. Moreover, this investigation develops four concepts for studying the low affinity binding site of $\alpha 4 \beta 2 \mathrm{nAChR}$ in the presence of ligand depletion and NSB that go beyond simply fitting total binding. First, binding of $\left[{ }^{3} \mathrm{H}\right] \mathrm{EB}$ to the low affinity site in saturation data or homologous competition data can be misattributed to NSB. Low-affinity specific binding can be identified by using larger maximum concentrations of $\left[{ }^{3} \mathrm{H}\right] \mathrm{EB}$ or cold competitor, simultaneously fitting apparent NSB, or obtaining data from multiple concentrations of $\alpha 4 \beta 2 \mathrm{nAChR}$. Potential ambiguity between low-affinity specific binding and NSB arises because they share a similar appearance as long as $R 2 \simeq R 2 T$. Increasing $\left[{ }^{3} \mathrm{H}\right] \mathrm{EB}_{\max }$ for saturation binding or increasing the maximum concentration of cold competitor for competition binding breaks this similarity by creating conditions for which $\mathrm{R} 2 \ll \mathrm{R} 2 \mathrm{~T}, \mathrm{R} 2 \mathrm{~L} \simeq \mathrm{R} 2 \mathrm{~T}$, and $\mathrm{R} 2 \mathrm{~B} \simeq \mathrm{R} 2 \mathrm{~T}$.

Second, when NSB is significant, ligand depletion can help characterize the low affinity site. Ligand depletion in binding studies is commonly believed to be only problematic. In contrast, increasing ligand depletion by increasing $\alpha 4 \beta 2 \mathrm{nAChR}$ concentration beneficially reduced NSB and significantly populated the low affinity site. The result was better detection of $\left[{ }^{3} \mathrm{H}\right] \mathrm{EB}$ binding to the low affinity site.

Third, directly measuring NSB without $\alpha 4 \beta 2 \mathrm{nAChR}$ can more reliably interpret NSB than does modeling NSB as a component of total binding in competition binding. Whether $\left[{ }^{3} \mathrm{H}\right] \mathrm{EB}$ binding at a particular large concentration of competitor arises solely from NSB depends on $K_{\mathrm{i} 2}$ and concentration of the low affinity site. Removing $\alpha 4 \beta 2 \mathrm{nAChR}$ from the assay, when feasible, is a more rigorous way than is using a large concentration of competitor to ensure that $\left[{ }^{3} \mathrm{H}\right] \mathrm{EB}$ binding arises from NSB and does not involve the low affinity site of $\alpha 4 \beta 2 \mathrm{nAChR}$.

Fourth, $\alpha_{\text {competitor }}$ needs to be considered when interpreting heterologous competition data with $\left[{ }^{3} \mathrm{H}\right] \mathrm{EB}$ and $\alpha 4 \beta 2$ nAChR because it increases $K_{\mathrm{i} 1 \text {, app }}$ and $K_{\mathrm{i} 2 \text {, app }}$. The true values of $K_{\mathrm{i} 1}$ and $K_{\mathrm{i} 2}$, therefore, can be determined only when $\alpha_{\text {competitor }}$ is known. Regardless of $\alpha_{\text {competitor }}$, however, $K_{\mathrm{i} 2 \text {, app }} / K_{\mathrm{i} 1 \text {, app }}$ is invariant and 
equals $K_{\mathrm{i} 2} / K_{\mathrm{i} 1}$. This ratio can help compare structural features of the two binding sites of $\alpha 4 \beta 2 \mathrm{nAChR}$. For example, variations in the ratio for a series of competitors with systematic structural variations might correlate with structural features of the two binding sites.

The findings presented in this study have limitations. First, modeling explored conditions suitable for characterizing low affinity binding that might not match conditions readily available in a laboratory. One such condition is nanomolar concentrations of $\alpha 4 \beta 2 \mathrm{nAChR}$. This high range of $\alpha 4 \beta 2 \mathrm{nAChR}$ concentration might be more available in the future with high level heterologous expression of $\alpha 4 \beta 2 \mathrm{nAChR}$. Quantitative results, such as concentration ranges that identify the low affinity site, are a reasonable but not definitive guide to conditions for studying the low affinity site of $\alpha 4 \beta 2 \mathrm{nAChR}$ with $\left[{ }^{3} \mathrm{H}\right] \mathrm{EB}$. For example, values of $\alpha$ might be substantially smaller than the values illustrating NSB in this study. With membrane homogenates from stably transfected HEK 293 cells, $\alpha$ was on the order of 0.001 [52]. In addition, changes in the fraction of low affinity site, as might occur with different expression conditions, will change the appearance of data. A larger fraction of low affinity site would make detection and analysis of this site easier. Second, the simulations included large numbers of data points with the goal of reliably describing binding data. Fewer data points would need higher precision in the data to identify the low affinity site and would lead to reduced precision of binding parameter estimates. Third, the properties of noise imposed on errorless data in this study do not necessarily reflect properties of real noise and uncertainties in experiments. Fourth, based on binding data from our laboratory [18], this study assumes two independent binding sites in $\alpha 4 \beta 2 \mathrm{nAChR}$. Other descriptions of binding sites (for example, two cooperative binding sites, a combination of cooperative and independent binding sites, or more than two independent sites) might better describe binding data from $\alpha 4 \beta 2 \mathrm{nAChR}$ under other conditions. Fifth, the linear relationship between free $\left[{ }^{3} \mathrm{H}\right] \mathrm{EB}$ and NSB led to the phenomenological and computational similarity between low affinity binding and NSB expressed in Eqs. (3)-(5). This linear relationship usually describes the behavior of NSB. This linear relationship might be unsuitable for some situations. For example, if NSB in the absence of specific binding is observed to be saturable [53-55], the linear relationship would need to be modified. Sixth, statistical comparisons using the F-test and $p$ values between the one site model $_{\text {total }}$ and two sites model total $_{\text {were suitable because }}$ of the nested nature of the two models. In other words,

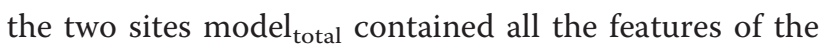
one site model total $_{\text {tal }}$ and extended those features by a second specific binding site. Other statistical methods for comparing models do not need nested models, such as Akaike's information criterion [7,56,57]. Seventh, the independent variable for the models in this study is the concentration of total ligand $\left(\left[{ }^{3} \mathrm{H}\right] \mathrm{EB}\right.$ for saturation binding or a cold ligand for competition). This variable usually is accurately known and was presumed to be free of uncertainty. Using the measured concentration of free ligand as the independent variable simplifies the model equations. The measured free ligand concentrations, however, will have nonnegligible uncertainty. The method of least squares might not reliably estimate parameter values when the values of the independent variable are uncertain $[1,2,58]$.

\section{Conclusions}

Characterizing the low affinity site potentially will contribute understanding of structure, function, and synthesis of $\alpha 4 \beta 2 \mathrm{nAChR}$ in native and heterologous expression systems. For example, the low affinity site might arise from an immature form of $\alpha 4 \beta 2 \mathrm{nAChR}$ or be involved in ligand-induced upregulation [32,59-61]. Heterologous competition data similar to Figure 12B were found with cytisine, nicotine, and acetylcholine as competitors of $\left[{ }^{3} \mathrm{H}\right] \mathrm{EB}$ binding with $\alpha 4 \beta 2 \mathrm{nAChR}$ immunoisolated with monoclonal antibody (mAb) 295 but not with other mAbs [18]. This similarity suggests that mAb 295 might isolate a distinctive form of low affinity $\alpha 4 \beta 2 \mathrm{nAChR}$. Homologous competition data might help further characterize this form of $\alpha 4 \beta 2$ nAChR. An intriguing possibility is that this low affinity form contributes to the biological roles of $\alpha 4 \beta 2 \mathrm{nAChR}$. This study should help investigators design experiments and develop computational approaches for interpreting data from $\left[{ }^{3} \mathrm{H}\right] \mathrm{EB}$ and $\alpha 4 \beta 2 \mathrm{nAChR}$ when ligand depletion and NSB are significant. Manipulation of maximum ligand and receptor concentrations and intentionally increasing ligand depletion are potentially helpful approaches. Extending the modeling and numerical solution method to three or more binding sites and to cooperative binding with ligand depletion and NSB is straightforward. Although applied specifically to $\left[{ }^{3} \mathrm{H}\right] \mathrm{EB}$ and $\alpha 4 \beta 2 \mathrm{nAChR}$, the methods should be relevant to other contexts of multiple binding sites, ligand depletion, and NSB.

\section{Abbreviations}

Cl: 95\% confidence interval; EB: epibatidine; mAb: monoclonal antibody; nAChR: nicotinic acetylcholine receptor; NSB: nonspecific binding; S/N: signal to noise ratio; SD: standard deviation; $\left[{ }^{3} \mathrm{H}\right] \mathrm{EB}:\left[{ }^{3} \mathrm{H}\right]$ epibatidine.

Acknowledgements

This study was financially supported by the Texas A\&M University System Health Science Center. 


\section{Author details}

'Department of Molecular and Cellular Medicine, Texas A\&M University System Health Science Center, College Station, TX 77843-1114, USA. ${ }^{2}$ Department of Neuroscience and Experimental Therapeutics, Texas A\&M University System Health Science Center, Bryan, TX 77807-3260, USA. ${ }^{3}$ Department of Veterinary Pathobiology, Texas A\&M University, College Station, TX 77843-4467, USA.

\section{Authors' contributions}

AP determined the observed binding constants describing $\left[{ }^{3} \mathrm{H}\right]$ epibatidine and nicotine binding to $a 4 \beta 2 n A C h R$ and edited the manuscript. GW conceived the study, created the models, analyzed the simulations, and wrote the manuscript. Both authors read and approved the final manuscript.

\section{Competing interests}

The authors declare that they have no competing interests.

Received: 7 June 2011 Accepted: 23 November 2011 Published: 23 November 2011

\section{References}

1. Johnson ML: The analysis of ligand-binding data with experimental uncertainties in the independent variables. Anal Biochem 1985, 148:471-478.

2. Tellinghuisen J: The least-squares analysis of data from binding and enzyme kinetics studies: weights, bias, and confidence intervals in usual and unusual situations. Methods Enzymol 2009, 467:499-529.

3. Carter CM, Leighton-Davies JR, Charlton SJ: Miniaturized receptor binding assays: complications arising from ligand depletion. J Biomol Screen 2007, 12:255-266.

4. Wells JW, Birdsall NJ, Burgen AS, Hulme EC: Competitive binding studies with multiple sites. Effects arising from depletion of the free radioligand. Biochimica et biophysica acta 1980, 632:464-469.

5. Hulme EC, Birdsall NJM: Strategy and tactics in receptor-binding studies. In Receptor-Ligand Interactions: A Practical Approach. Edited by: Hulme EC. New York, NY: Oxford University Press; 1992:63-176, The Practical Approach Series.

6. Munson PJ, Rodbard D: Ligand: a versatile computerized approach for characterization of ligand-binding systems. Anal Biochem 1980, 107:220-239.

7. Motulsky HJ, Christopoulos A: Fitting models to biological data using linear and nonlinear regression. A practical guide to curve fitting New York, NY: Oxford University Press; 2004

8. Avlani VA, McLoughlin DJ, Sexton PM, Christopoulos A: The impact of orthosteric radioligand depletion on the quantification of allosteric modulator interactions. J Pharmacol Exp Ther 2008, 325:927-934.

9. Wang ZX, Jiang RF: A novel two-site binding equation presented in terms of the total ligand concentration. FEBS Lett 1996, 392:245-249.

10. Gnädisch D, London ED, Terry P, Hill GR, Mukhin AG: High affinity binding of $\left[{ }^{3} \mathrm{H}\right]$ epibatidine to rat brain membranes. Neuroreport 1999 , 10:1631-1636.

11. Eaton JB, Peng JH, Schroeder KM, George AA, Fryer JD, Krishnan C, Buhlman L, Kuo YP, Steinlein O, Lukas RJ: Characterization of human a $4 \beta 2$-nicotinic acetylcholine receptors stably and heterologously expressed in native nicotinic receptor-null SH-EP1 human epithelial cells. Mol Pharmacol 2003, 64:1283-1294.

12. Shafaee $N$, Houng M, Truong A, Viseshakul N, Figl A, Sandhu S, Forsayeth JR, Dwoskin LP, Crooks PA, Cohen BN: Pharmacological similarities between native brain and heterologously expressed a4 $\beta 2$ nicotinic receptors. Br J Pharmacol 1999, 128:1291-1299.

13. Houghtling RA, Dávila-García MI, Hurt SD, Kellar KJ: $\left[{ }^{3} \mathrm{H}\right]$ Epibatidine binding to nicotinic cholinergic receptors in brain. Med Chem Res 1994, 4:538-546.

14. Truong A, Xing X, Forsayeth JR, Dwoskin LP, Crooks PA, Cohen BN: Pharmacological differences between immunoisolated native brain and heterologously expressed rat a4 $\beta 2$ nicotinic receptors. Brain Res $\mathrm{Mol}$ Brain Res 2001, 96:68-76.

15. Whiteaker $P$, Sharples CG, Wonnacott S: Agonist-induced up-regulation of a4 $\beta 2$ nicotinic acetylcholine receptors in M10 cells: pharmacological and spatial definition. Mol Pharmacol 1998, 53:950-962
16. Jett DA, Beckles RA, Navoa RV, McLemore GL: Increased high-affinity nicotinic receptor-binding in rats exposed to lead during development. Neurotoxicol Teratol 2002, 24:805-811.

17. Karadsheh MS, Shah MS, Tang X, Macdonald RL, Stitzel JA: Functional characterization of mouse $a 4 \beta 2$ nicotinic acetylcholine receptors stably expressed in HEK293T cells. J Neurochem 2004, 91:1138-1150.

18. Person AM, Bills KL, Liu H, Botting SK, Lindstrom J, Wells GB: Extracellular domain nicotinic acetylcholine receptors formed by $\alpha 4$ and $\beta 2$ subunits. J Biol Chem 2005, 280:39990-40002.

19. Swillens S: Interpretation of binding curves obtained with high receptor concentrations: practical aid for computer analysis. Mol Pharmacol 1995, 47:1197-1203.

20. Marks MJ, Meinerz NM, Drago J, Collins AC: Gene targeting demonstrates that a4 nicotinic acetylcholine receptor subunits contribute to expression of diverse $\left[{ }^{3} \mathrm{H}\right]$ epibatidine binding sites and components of biphasic ${ }^{86} \mathrm{Rb}^{+}$efflux with high and low sensitivity to stimulation by acetylcholine. Neuropharmacology 2007, 53:390-405.

21. Nelson ME, Kuryatov A, Choi $\mathrm{CH}$, Zhou Y, Lindstrom J: Alternate stoichiometries of a $4 \beta 2$ nicotinic acetylcholine receptors. Mol Pharmacol 2003, 63:332-341.

22. Marks MJ, Whiteaker P, Calcaterra J, Stitzel JA, Bullock AE, Grady SR, Picciotto MR, Changeux J-P, Collins AC: Two pharmacologically distinct components of nicotinic receptor-mediated rubidium efflux in mouse brain require the $\beta 2$ subunit. J Pharmacol Exp Ther 1999, 289:1090-1103.

23. Butt CM, Hutton SR, Marks MJ, Collins AC: Bovine serum albumin enhances nicotinic acetylcholine receptor function in mouse thalamic synaptosomes. J Neurochem 2002, 83:48-56.

24. Buisson B, Bertrand D: Chronic exposure to nicotine upregulates the human $\alpha 4 \beta 2$ nicotinic acetylcholine receptor function. J Neurosci 2001, 21:1819-1829.

25. Zwart R, Vijverberg HP: Four pharmacologically distinct subtypes of a $4 \beta 2$ nicotinic acetylcholine receptor expressed in Xenopus laevis oocytes. $\mathrm{Mol}$ Pharmacol 1998, 54:1124-1131.

26. Sidach SS, Fedorov NB, Lippiello PM, Bencherif M: Development and optimization of a high-throughput electrophysiology assay for neuronal a4B2 nicotinic receptors. J Neurosci Methods 2009, 182:17-24.

27. Vallejo YF, Buisson B, Bertrand D, Green WN: Chronic nicotine exposure upregulates nicotinic receptors by a novel mechanism. J Neurosci 2005, 25:5563-5572.

28. Moroni M, Zwart R, Sher E, Cassels BK, Bermudez I: a4ß2 nicotinic receptors with high and low acetylcholine sensitivity: pharmacology, stoichiometry, and sensitivity to long-term exposure to nicotine. $\mathrm{Mol}$ Pharmacol 2006, 70:755-768.

29. Briggs CA, Gubbins EJ, Putman CB, Thimmapaya R, Meyer MD, Surowy CS: High- and low-sensitivity subforms of $\alpha 4 \beta 2$ and $a 3 \beta 2$ nAChRs. Journal of Molecular Neuroscience 2006, 30:11-12.

30. Zhou Y, Nelson ME, Kuryatov A, Choi C, Cooper J, Lindstrom J: Human a4 $\beta 2$ acetylcholine receptors formed from linked subunits. J Neurosci 2003, 23:9004-9015.

31. Covernton PJO, Connolly JG: Multiple components in the agonist concentration-response relationships of neuronal nicotinic acetylcholine receptors. J Neurosci Methods 2000, 96:63-70.

32. Kuryatov A, Luo J, Cooper J, Lindstrom J: Nicotine acts as a pharmacological chaperone to up-regulate human a4 $\beta 2$ acetylcholine receptors. Mol Pharmacol 2005, 68:1839-1851.

33. Zwart R, Broad LM, Xi Q, Lee M, Moroni M, Bermudez I, Sher E: 5-I A-85380 and TC-2559 differentially activate heterologously expressed a4 $\beta 2$ nicotinic receptors. Eur J Pharmacol 2006, 539:10-17.

34. Tapia L, Kuryatov A, Lindstrom J: $\mathrm{Ca}^{2+}$ permeability of the $(\alpha 4)_{3}(\beta 2)_{2}$ stoichiometry greatly exceeds that of $(\alpha 4)_{2}(\beta 2)_{3}$ human acetylcholine receptors. Mol Pharmacol 2007, 71:769-776.

35. Anderson DJ, Malysz J, Grønlien JH, El Kouhen R, Håkerud M, Wetterstrand C, Briggs CA, Gopalakrishnan M: Stimulation of dopamine release by nicotinic acetylcholine receptor ligands in rat brain slices correlates with the profile of high, but not low, sensitivity alpha4beta2 subunit combination. Biochem Pharmacol 2009, 78:844-851.

36. Carbone AL, Moroni M, Groot-Kormelink PJ, Bermudez I: Pentameric concatenated $(\alpha 4)_{2}(\beta 2)_{3}$ and $(\alpha 4)_{3}(\beta 2)_{2}$ nicotinic acetylcholine receptors: subunit arrangement determines functional expression. $\mathrm{Br} J$ Pharmacol 2009, 156:970-981. 
37. Exley R, Moroni M, Sasdelli F, Houlihan LM, Lukas RJ, Sher E, Zwart R, Bermudez I: Chaperone protein 14-3-3 and protein kinase $A$ increase the relative abundance of low agonist sensitivity human a $4 \beta 2$ nicotinic acetylcholine receptors in Xenopus oocytes. J Neurochem 2006, 98:876-885.

38. Houlihan LM, Slater Y, Guerra DL, Peng JH, Kuo YP, Lukas RJ, Cassels BK, Bermudez l: Activity of cytisine and its brominated isosteres on recombinant human $\alpha 7, \alpha 4 \beta 2$ and $\alpha 4 \beta 4$ nicotinic acetylcholine receptors. J Neurochem 2001, 78:1029-1043.

39. Khiroug SS, Khiroug L, Yakel JL: Rat nicotinic acetylcholine receptor a2 $\beta 2$ channels: comparison of functional properties with a4 $\beta 2$ channels in Xenopus oocytes. Neuroscience 2004, 124:817-822.

40. Gotti C, Moretti M, Meinerz NM, Clementi F, Gaimarri A, Collins AC, Marks MJ: Partial deletion of the nicotinic cholinergic receptor a 4 or $\beta 2$ subunit genes changes the acetylcholine sensitivity of receptormediated ${ }^{86} \mathrm{Rb}^{+}$efflux in cortex and thalamus and alters relative expression of a4 and $\beta 2$ subunits. Mol Pharmacol 2008, 73:1796-1807.

41. Li $P$, Steinbach $J H$ : The neuronal nicotinic $a 4 \beta 2$ receptor has a high maximal probability of being open. Br J Pharmacol 2010, 160:1906-1915.

42. Houghtling RA, Dávila-García MI, Kellar KJ: Characterization of $( \pm)-\left[{ }^{3} \mathrm{H}\right]$ epibatidine binding to nicotinic cholinergic receptors in rat and human brain. Mol Pharmacol 1995, 48:280-287.

43. Marks MJ, Whiteaker P, Collins AC: Deletion of the $\alpha 7, \beta 2$, or $\beta 4$ nicotinic receptor subunit genes identifies highly expressed subtypes with relatively low affinity for $\left[{ }^{3} \mathrm{H}\right]$ epibatidine. Mol Pharmacol 2006, 70:947-959.

44. Srivastava S, Hamouda AK, Pandhare A, Duddempudi PK, Sanghvi M, Cohen JB, Blanton MP: $\left[{ }^{3} \mathrm{H}\right]$ Epibatidine photolabels non-equivalent amino acids in the agonist binding site of Torpedo and $\alpha 4 \beta 2$ nicotinic acetylcholine receptors. J Biol Chem 2009, 284:24939-24947.

45. Hulme EC, Trevethick MA: Ligand binding assays at equilibrium: validation and interpretation. Br J Pharmacol 2010, 161:1219-1237.

46. Chanvorachote B, Nimmannit U, Muangsiri W, Kirsch L: An evaluation of a fluorometric method for determining binding parameters of drug-carrier complexes using mathematical models based on total drug concentration. J Fluoresc 2009, 19:747-753.

47. Andujar-Sánchez M, Jara-Perez V, Cobos ES, Cámara-Artigas A: A thermodynamic characterization of the interaction of 8-anilino-1naphthalenesulfonic acid with native globular proteins: the effect of the ligand dimerization in the analysis of the binding isotherms. $J \mathrm{Mol}$ Recognit 2011, 24:548-556.

48. Beyer WH: Standard Mathematical Tables Cleveland, Ohio: CRC Press; 1976.

49. Motulsky HJ, Ransnas LA: Fitting curves to data using nonlinear regression: a practical and nonmathematical review. FASEB J 1987, 1:365-374.

50. Cuatrecasas $P$, Hollenberg MD: Membrane receptors and hormone action. Adv Protein Chem 1976, 30:251-451.

51. Cheng $Y$, Prusoff $W H$ : Relationship between the inhibition constant $\left(K_{1}\right)$ and the concentration of inhibitor which causes 50 per cent inhibition $\left(I_{50}\right)$ of an enzymatic reaction. Biochem Pharm 1973, 22:3099-3108.

52. Xiao Y, Kellar KJ: The comparative pharmacology and up-regulation of rat neuronal nicotinic receptor subtype binding sites stably expressed in transfected mammalian cells. J Pharmacol Exp Ther 2004, 310:98-107.

53. Mendel CM, Mendel DB: 'Non-specific' binding. The problem, and a solution. Biochem J 1985, 228:269-272.

54. Reed RG: Spurious cell surface receptors: inadequate correction for saturable, nonspecific binding mimics receptor binding. Anal Biochem 1990, 185:160-163.

55. McLure JA, Miners JO, Birkett DJ: Nonspecific binding of drugs to human liver microsomes. Br J Clin Pharmacol 2000, 49:453-461.

56. Burnham KP, Anderson DR: Model selection and multimodel inference: A practical information-theoretic approach. second edition. New York: Springer; 2002.

57. Ludden TM, Beal SL, Sheiner LB: Comparison of the Akaike information criterion, the Schwarz criterion and the $F$ test as guides to model selection. J Pharmacokinet Biopharm 1994, 22:431-445.

58. Johnson ML, Frasier SG: Nonlinear least-squares analysis. Methods Enzymol 1985, 117:301-342

59. Kishi $M$, Steinbach $\mathrm{JH}$ : Role of the agonist binding site in up-regulation of neuronal nicotinic a4 $\beta 2$ receptors. Mol Pharmacol 2006, 70:2037-2044.
60. Sallette J, Pons S, Devillers-Thiery A, Soudant M, Prado de Carvalho L, Changeux J-P, Corringer P-J: Nicotine upregulates its own receptors through enhanced intracellular maturation. Neuron 2005, 46:595-607.

61. Gahring LC, Vasquez-Opazo GA, Rogers SW: Choline promotes nicotinic receptor a4 + $\beta 2$ up-regulation. J Biol Chem 2010, 285:19793-19801.

doi:10.1186/2046-1682-4-19

Cite this article as: Person and Wells: Characterizing low affinity epibatidine binding to $\alpha 4 \beta 2$ nicotinic acetylcholine receptors with ligand depletion and nonspecific binding. BMC Biophysics 2011 4:19.

\section{Submit your next manuscript to BioMed Central and take full advantage of:}

- Convenient online submission

- Thorough peer review

- No space constraints or color figure charges

- Immediate publication on acceptance

- Inclusion in PubMed, CAS, Scopus and Google Scholar

- Research which is freely available for redistribution

Submit your manuscript at www.biomedcentral.com/submit
C) Biomed Central 